\title{
AVALIAÇAO DAS CONDIÇÕES DE TRABALHO E DA EXPOSIÇÃO À VIBRAÇAO DO OPERADOR DE MÁQUINAS NA COLHEITA FLORESTAL
}

\section{ROSA YASUKO YAMASHITA}

Engenheira Agrônoma

Orientador: Prof. Dr. FERNANDO SEIXAS

Dissertação apresentada à Escola Superior de Agricultura "Luiz de Queiroz", Universidade de São Paulo, para obtenção do título de Mestre em Ciências, Área de Concentração: Ciências Florestais.

P I R A C I C A B A

Estado de São Paulo - Brasil

Fevereiro - 2002 
Dados Internacionais de Catalogação na Publicação (CIP) DIVISÃO DE BIBLIOTECA E DOCUMENTAÇĀO - ESALQ/USP

\section{Yamashita, Rosa Yasuko}

Avaliação das condições de trabalho e da exposição à vibração do operador de máquinas na colheita florestal / Rosa Yasuko Yamashita. - - Piracicaba, 2002.

$55 \mathrm{p}$.

Dissertação (mestrado) - - Escola Superior de Agricultura Luiz de Queiroz, 2002. Bibliografia.

1. Colheita 2. Ergonomia 3. Inovações tecnológicas 3. Máquinas agrícolas 4. Mecanização florestal 5 . Segurança no trabalho I. Título

CDD 634.98 


\section{DEDICATÓRIA}

Ao meu pai (in memorian), a minha mãe meus irmãos pela luta e dedicação na minha formação. Ao meu marido pelo amor, carinho e compreensão. 


\section{AGRADECIMENTOS}

Ao professor Fernando Seixas pela orientação e consideração.

A FUNDACENTRO pelo incentivo ao nosso aprimoramento.

Aos amigos da Coordenação de Segurança Rural, pesquisadores José Prado Alves Filho e Eduardo Garcia Garcia pela colaboração, incentivo e companheirismo; em especial ao pesquisador Irlon de Ângelo da Cunha pela paciência didática e apoio na realização dos ensaios de campo; a Leila Cristina Alves Lima, Maria Aparecida Silva Neto, Adriana Aparecida Souza Silva pela consideração e apoio.

A pesquisadora e amiga Raffaella Rossetto e ao amigo Carlos Alberto Oliveira Matos pelo apoio e dedicação.

A Empresa Duraflora que possibilitou os nossos trabalhos de campo e também os seus técnicos e operadores de máquinas.

Á todos da FUNDACENTRO e da ESALQ que de alguma forma contribuíram para a realizaçao deste trabalho. 


\section{SUMÁRIO}

Página

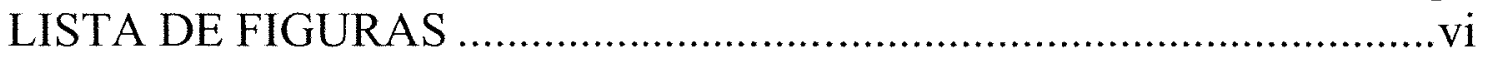

LISTA DE TABELAS ................................................................... vii

LISTA DE SIGLAS E ABREVIATURAS ............................................ viii

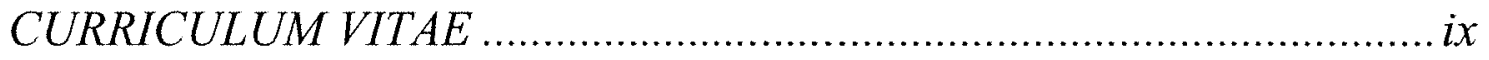

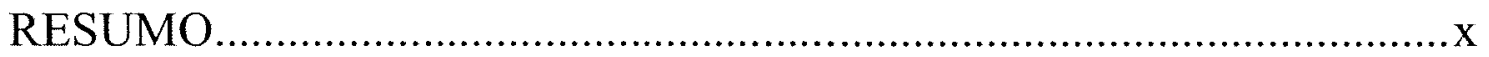

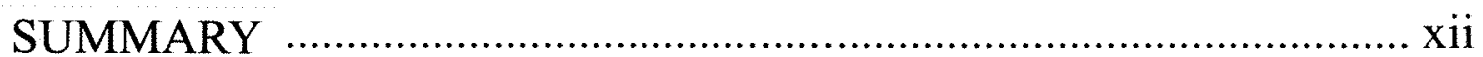

1 INTRODUÇÃO

2 REVISÃO DE LITERATURA …….......................................................11

2.1 Panorama do setor florestal e o mercado brasileiro ..............................11

2.2 Panorama dos acidentes do trabalho .....................................................

2.2.1. Acidentes e doenças do trabalho no mundo ......................................14

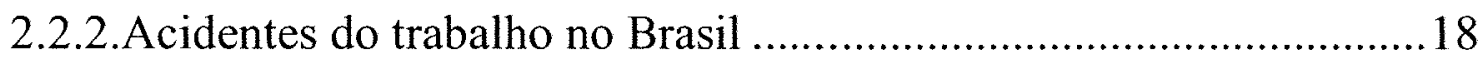

2.3 Efeitos à saúde pela exposição à vibração ............................................25

2.4 Efeitos à saúde ocasionados pelo trabalho em turnos ..........................29

2.5 Influência das características individuais no desempenho

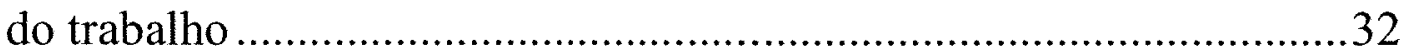

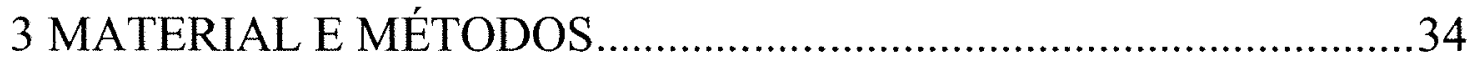

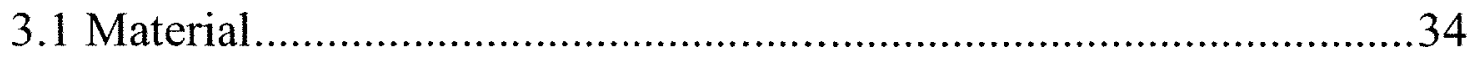

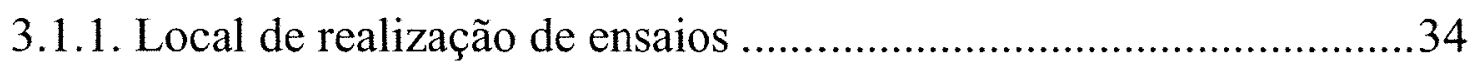

3.1.2 Intrumental utilizado para medição de vibração ................................35

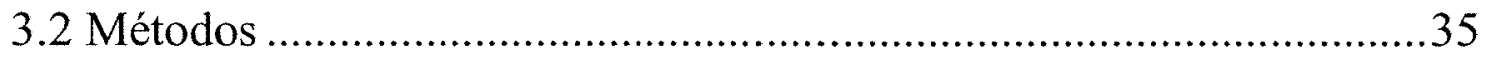

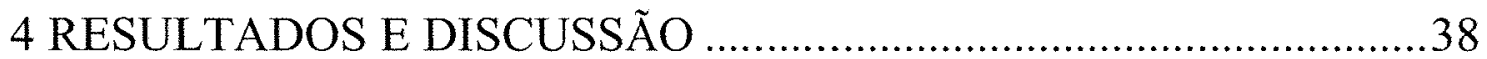

4.1 Características da atividade de campo...................................................40 
4.2 Descrição das máquinas avaliadas e dos operadores

4.3 Resultado das avaliações de exposição à vibração de corpo inteiro ...42 5 CONCLUSÕES 


\section{LISTA DE FIGURAS}

Página

1 Esboço conceitual de um programa para prevenção de distúrbios ocasioandos pela vibração........................................... 28

2 Deterioração da saúde com a idade dos trabalhadores por turnos e trabalhadores diurnos............................................. 31

3 Fixação do acelerômetro no assento da máquina............................... 36

4 Fixação do medidor de vibração na cabine da máquina........................ 37

5 Esquema do empilhamento das toras após a derrubada

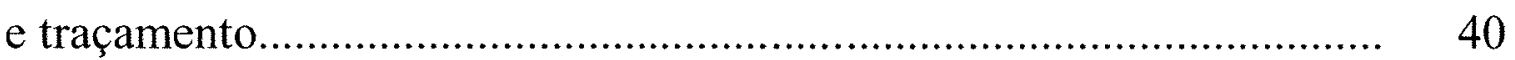

6 Limites para as acelerações transversais X,Y................................... 46

7 Limites para as acelerações longitudinais Z.................................... 46 


\section{LISTA DE TABELAS}

Página

1 Área total reflorestada no Brasil (ha) - 1999 ........................................ 12

2 Produção de base florestal no Brasil - 1999............................................ 13

3 Distribuição dos pobres no Brasil, 1997............................................... 18

4 Distribuição da população rural e urbana pelas regiões do Brasil, em 1996 ............................................................. 19

5 Distribuição das pessoas ocupadas, de 10 anos ou mais de idade, por ramo de atividade econômica da ocupação principal, Brasil, 1996........................................................ 20

6 Pessoas ocupadas e trabalhadores registrados pelo Instituto Nacional de Seguridade Social - INSS, Brasil, 1996 ........................... 22

7 Acidentes registrados pelo INSS em 1996 ............................................ 23

8 Distribuição da freqüência e do coeficiente ${ }^{1}$ dos acidentes fatais $^{2}$ em decorrência de acidentes de trabalho no Brasil, segundo as classes de atividades econômicas, 1997

9 Sintomas de exposição à vibração de corpo inteiro nas

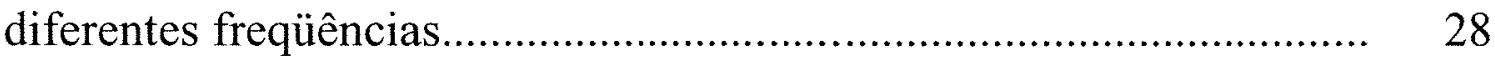

10 Dados da avaliação da exposição à vibração......................................... 44 


\section{LISTA DE SIGLAS E ABREVIATURAS}

DSST

ESALQ/USP

FAO

FUNDACENTRO

IBGE

INSS

MPAS

MTE

OIT

OMS

SBS
Departamento de Segurança e Saúde no Trabalho, Ministério do Trabalho e Emprego

Escola Superior de Agricultura Luiz de Queiroz, da Universidade de São Paulo

Organizaçao das Naçoes Unidas para a Agricultura e Alimentação

Fundação Jorge Duprat Figueiredo de Segurança e Medicina do Trabalho, Ministério do Trabalho e Emprego

Instituto Brasileiro de Geografia e Estatística

Instituto Nacional de Seguridade Social

Ministério da Previdência e Assitência Social

Ministério do Trabalho e Emprego

Organização Internacional do Trabalho

Organização Mundial da Saúde

Sociedade Brasileira de Silvicultura 


\section{CURRICULUM VITAE}

Rosa Yasuko Yamashita

Local e data de nascimento: São Paulo/SP, 19/10/1953

Formação universitária:

Engenheira Agrônoma, ESALQ/USP, Piracicaba/SP, 1981

Ergonomista, Instituto de Psicologia/USP, São Paulo/SP, 1986

Engenheira de Segurança do Trabalho, Fundação Armando Álvares

Penteado -FAAP, São Paulo/SP, 1988

\section{Trabalhos publicados relacionados à dissertação:}

1. CUNHA, I.A; YAMASHITA, R.Y.; CORRÊA, I.M.; MAZIERO, J.V.G., MACIEL, S. Avaliação do ruído e vibração em motosserras: resultados parciais. In: Bragantia, Campinas, SP, 57(1): 193-196, 1998.

2. CUNHA, I.A; YAMASHITA, R.Y.; CORRÊA, I.M.; MAZIERO, J.V.G. Utilização dos níveis de vibração e ruído na comparação e seleção de motosserras e suas implicações na exposição ocupacional dos operadores. In: XV Congresso Mundial sobre Segurança e Saúde no Trabalho, São Paulo, SP., abril de 1999.

4. GARCIA, E. G. e YAMASHITA, R. Y. Panorama de accidentes y enfermidades en el trabajo rural en el Brasil . Educación Obrera 2000/1-2, n ${ }^{\circ} \mathrm{s} 118 / 119$, Oficina Internacional del Trabajo - OIT, p. 84-92, Ginebra, Suiza. Junho de 2000 


\title{
AVALIAÇÃO DAS CONDIÇÕES DE TRABALHO E DA EXPOSIÇÃO À VIBRAÇÃO DO OPERADOR DE MÁQUINAS NA COLHEITA FLORESTAL
}

\author{
Autora: ROSA YASUKO YAMASHITA \\ Orientador: Prof. Dr. FERNANDO SEIXAS
}

\section{RESUMO}

O presente trabalho teve como objetivo avaliar a exposição do operador à vibração emitida pelas máquinas de colheita em situação de trabalho normal e discutir os efeitos potenciais da exposição à vibrações de corpo inteiro e as condições de segurança no local de trabalho. Partiu-se do pressuposto de que a modernização do setor florestal, com a introdução de novas tecnologias trouxe benefícios aos trabalhadores, mas trouxe também efeitos nocivos a sua segurança e saúde antes desconhecidos. A avaliação da exposição à vibração foi realizada com base em normas internacionais e os resultados das avaliações mostraram que algumas máquinas utilizadas na colheita florestal necessitam de um estudo mais aprofundado para a definição da jornada de trabalho, em particular a máquina utilizada para o carregamento de madeira (forwarder), que não prejudiquem a saúde dos operadores ao longo de sua vida 
laboral. Os efeitos nocivos da vibração à saúde humana são notórios, conforme pode-se observar nos trabalhos pesquisados, entretanto, uma quantificação precisa dos seus efeitos ainda șão amplamente discutidos, inclusive nas normas internacionais, devido a variaveis de característica sinergistica e de longo prazo que estão relacionadas com outros fatores de riscos presentes na atividade florestal. 


\title{
EVALUATION OF WORK CONDITIONS AND VIBRATION EXPOSURE OF MACHINES OPERATOR IN FOREST HARVEST
}

\author{
Autora: ROSA YASUKO YAMASHITA \\ Orientador: Prof. Dr. FERNANDO SEIXAS
}

\section{SUMMARY}

The present work had as objective to evaluate the exhibition of the operator to the vibration emitted by the crop machines in situation of normal work and to discuss the potential effects of the exhibition to vibrations of whole body and safety's conditions in the work place. It assumes the presupposition that the modernization of the forestry activities with the introduction of new technologies brought benefits to the workers, but also brought noxious effects to its safety and health formerly ignored. The evaluation of the exhibition to the vibration was accomplished with base in international norms and the results of the evaluations showed that some machines used in the forest harvest need a study more deepened for the definition of the working day, in particular the machine used for the wood shipment (forwarder), that don't harm the health of the operators along its life 
laboral. The noxious effects of the vibration to the human health are notorious, as it can be observed in the researched works, however, a precise quantification of its effects is still discussed thoroughly, besides in the international norms, due to variables of characteristic sinergistic and of long term that are related with other factors of present risks in the forest activity. 


\section{INTRODUÇÃO}

O incremento das atividades desenvolvidas no setor florestal, no final da década de 80 e início dos anos 90, incorporou formas de trabalho diferenciadas no setor rural com características de organização de trabalho semelhantes as do setor urbano, devido ao incremento da mão-de-obra assalariada. As novas formas de organização apareceram para atender as demandas da indústria de transformação do produto "in natura" em produtos de consumo industrial e urbano.

A organização de trabalho na "agroindústria" de papel e celulose se assemelha à organização do trabalho na exploração do café no início do século XIX, com a introdução do capital urbano para o desenvolvimento rural, com o processo de diferenciação das estruturas de organização familiar das explorações agrícolas no Brasil e a conseqüente necessidade de mão-deobra assalariada, que apesar de ter estabelecimento domiciliar no setor urbano possuísse um certo grau de conhecimento das tarefas a serem executadas no campo.

Esta nova forma de organização trouxe benefícios ao trabalhador assalariado através dos benefícios sociais previstos nas orientações presentes na Consolidação das Leis do Trabalho - CLT. Entretanto, a fragmentação do 
trabalho, característica do trabalho capitalista e as novas exigências de produção geraram outros problemas para o trabalhador, interferindo na sua qualidade de vida e na sua segurança.

O desenvolvimento dos setores agrícola e florestal, assim como dos demais setores da economia, vem exigindo o emprego de novas tecnologias, num processo cada vez mais acelerado. A introdução de novas tecnologias no campo como, por exemplo, o uso de máquinas e equipamentos no desenvolvimento das atividades florestais trouxe alívio ao trabalho humano, no entanto, a transferência de tecnologia não veio acompanhada de estudos prévios sobre seus impactos ao ambiente e ao homem e que levassem em consideração os valores sociais e culturais locais e, em especial, as características individuais dos usuários, o que acarretou como conseqüência o aumento da ocorrência do número de acidentes graves e fatais, Garcia \& Yamahita (2000), observações que são concordantes àquelas emitidas por organizações internacionais:

"A transferência de tecnologia não se limita ao conhecimento de como funcionam ou como se utilizam as máquinas, os produtos e os procedimentos, mas ao contrário trata-se de ampliar esse conhecimento com respeito aos efeitos que a tecnologia transferida pode ter sobre a segurança, a saúde e as condições de trabalho de quem as utilizam (Organização Internacional do Trabalho-OIT, 1988)”.

"A transferência de tecnologia dos países industrializados para os países em desenvolvimento é um aspecto a ser considerado, pois apesar das melhorias obtidas nos países industrializados, estas nem sempre correspondem às características necessárias aos países em desenvolvimento, 
ou seja, a transferência de tecnologia nem sempre obedece à transferência de ergonomia" (FAO, 1992).

No Brasil, a partir da década de 90 , com a necessidade de diminuição dos custos operacionais provocada em parte pela concorrência representada pelo mercado externo, com a introdução do certificado de qualidade da International Organization for Standardization - ISO - 9000e com a abertura para a importação de máquinas, houve uma aceleração na mecanização por parte de muitas empresas, buscando ganhos de produtividade e melhoria da qualidade, Roesler (1994).

Com a concorrência representada pelo mercado externo, a necessidade de redução de custos operacionais e a redução de mão-de-obra em algumas localidades, muitas empresas vêm adotando o emprego de modernas tecnologias para possibilitar a otimização do sistema. O processo mecanizado já é realidade em muitas unidades de produção agrícola e florestal, principalmente nas áreas mais planas onde a operação encontra maior viabilidade.

Diversos fatores como a localização e a diversificação das áreas de exploração, considerando-se os fatores climáticos, a topografia, a disponibilidade de mão-de-obra qualificada e a relação custo benefício tem diferenciado as empresas em relação às características de emprego de manejo e tecnologia: enquanto algumas empregam alta tecnologia e, conseqüentemente adotam um manejo altamente mecanizado, outras utilizam métodos mais rudimentares de exploração florestal, com o uso intensivo de motosserras. 
O uso de motosserras na colheita florestal tem provocado graves acidentes com mutilações, algumas vezes fatais, devido à falta de dispositivos de segurança dos equipamentos, a falta de organização do trabalho e de treinamento dos trabalhadores. A falta de equipamentos de proteção individual também tem contribuído para a gravidade dos acidentes e doenças. Esse panorama motivou a elaboração de uma norma específica sobre a fabricação, o uso e a comercialização desse equipamento no Brasil, através das Portarias números 13 e 14, de 22 de outubro de 1994, do Ministério do Trabalho e Emprego contemplando os aspectos de segurança e de treinamento dos operadores, inaugurando a partir deste momento a metodologia de negociação tripartite (representações de trabalhadores, empregadores e governo) para a elaboração e implantação de normas técnicas no setor rural pelo Ministério do Trabalho e Emprego Cleverson et al. (1994).

Em 1994, a Fundação Jorge Duprat Figueiredo de Segurança e Medicina do Trabalho - FUNDACENTRO realizou um levantamento em onze empresas de reflorestamento nos Estados de São Paulo, Paraná, Santa Catarina, Rio Grande do Sul, Espírito Santo, Bahia e Minas Gerais para mapear os principais fatores de riscos à segurança e à saúde presentes no desenvolvimento dos trabalhos no setor florestal. Verificou-se a presença de precárias condições de trabalho em algumas empresas, contrapondo-se a outras com melhor desempenho e preocupação com a melhoria das condições de trabalho.

A atividade florestal, à semelhança da exploração agrícola, tem exposto o trabalhador a diversos riscos à sua saúde e segurança. Os fatores de riscos na área rural estão presentes desde o transporte dos trabalhadores ao local de 
trabalho com o uso de transporte na maioria das vezes precário em caminhões ou em ônibus muitas vezes descartados do setor urbano e sem manutenção que é agravado pelo transporte de equipamentos e ferramentas conjuntamente com os trabalhadores; no desenvolvimento das tarefas a céu aberto com a exposição a agentes climáticos como a radiação solar, excesso de calor ou frio, a chuvas e raios, a poeiras, ao ataque de animais peçonhentos como serpentes, aranhas, escorpiões, abelhas, formigas e lagartas; aos riscos de quedas em desnível; aos riscos de acidentes provocados por queda de galhos e árvores; a grande diversificação de métodos de trabalho realizados manualmente ou mecanicamente e ainda pela realização de tarefas em condições precárias de vida, higiene, saúde e educação, FUNDACENTRO (1986).

Outros agentes de riscos estão presentes, como o uso de produtos químicos na forma de insumos (fertilizantes químicos, herbicidas, inseticidas, formicidas e fungicidas) os quais têm sido responsáveis por alergias, doenças crônicas e intoxicações graves e no uso de máquinas e equipamentos sem dispositivos de segurança, expondo o trabalhador a acidentes graves e às vezes fatais, bem como a exposição a ruídos e vibrações emitidas pelas máquinas, a inadequação das posições de trabalho; a fadiga e ao estresse decorrentes da carga de trabalho e da monotonia.

Em atividades consideradas mais leves, normalmente executadas por mulheres, como nos viveiros e no plantio de mudas, a longa duração do trabalho em posições inadequadas e a realização de movimentos repetitivos, podem ocasionar lesões por esforços repetitivos. Porém o registro dessas ocorrências ainda não é feito de forma sistemática e abrangente, mas os levantamentos localizados têm apontado a gravidade desses eventos. 
$\mathrm{Na}$ extração de resina de pinus há casos de alergia de pele, principalmente nas mãos. Na produção de carvão vegetal para siderurgia há a exposição do trabalhador ao calor intenso, as fuligens, a outras adversidades dos locais de trabalho. Alem de, em alguns locais terem sido detectados o emprego da mão-de-obra infantil e do trabalho semi-escravo.

As condições adequadas de alojamento com local para alimentação e higienização, disponibilidade de água potável nas frentes de trabalho não são uma realidade na maioria das empresas.

As pequenas propriedades agrícolas que atuam como fornecedoras de matéria prima para as grandes empresas de papel e celulose, recebem mudas e orientação para a boa condução da cultura. A oferta de tecnologia, de mudas e de garantia da comercialização do produto não inclui a oferta de serviços em gestão de segurança e saúde. Como no setor agrícola, os pequenos produtores agrícolas estão inseridos dentro da economia informal, os acidentes e doenças que possam ocorrer na unidade agrícola não são notificados e portanto, não constam das estatísticas de acidentes decorrentes do trabalho.

Ao considerarmos que a grande massa de trabalhadores do setor rural encontra-se no setor informal, devemos nos valer como referência dos muitos estudos de casos realizados para mapear as conseqüências da exposição aos agentes de riscos já estudados e de observações em campo da situação real de trabalho para a obtenção de alguns dados com o recurso de metodologias amplamente conhecidas.

O uso da terceirização de serviços no setor florestal é intenso e apesar de sua iniciativa preconizar o maior nível de profissionalização dos serviços prestados e a conseqüente demanda de tecnologias mais modernas, a 
terceirização no setor florestal, iniciada na década de 80 , trouxe o aumento de acidentes e a perda de qualidade de serviços e de produtos, devido a falta de investimento, por parte dos agentes da terceirização, na manutenção de máquinas, na organização do trabalho e na capacitação da mão-de-obra. Atualmente está havendo uma mudança no conceito de parcerias, com a participação das empresas contratantes na capacitação e no treinamento de trabalhadores e no financiamento de máquinas e equipamentos. A competitividade e o processo de certificação florestal tem melhorado o sistema de terceirização, Yamashita (1997).

As limitações oferecidas pela carência de legislação específica para a fabricação, a comercialização e o uso de máquinas e equipamentos no setor rural, a falta de consciência de alguns setores empresariais de que a qualidade de vida no trabalho influencia positivamente na produtividade, o grau de instrução dos operadores de máquinas, bem como a ausência, muitas vezes, dos conceitos de segurança e ergonomia nos currículos escolares das escolas agrotécnicas, e notadamente a falta de estatísticas de acidentes e de doenças decorrentes do trabalho rural, pela falta de notificação de acidentes do trabalho por desconhecimento do assunto ou pela omissão de outros, agravados pela grande massa trabalhadora no setor informal torna o planejamento de trabalhos de prevenção muito mais difíceis e de projeções muito subestimadas acerca dos prejuízos causados à saúde dos trabalhadores no setor.

A Organização Internacional do Trabalho - OIT, no período de 1998 1999, levantou a discussão no Brasil acerca da possibilidade de criação de um código de práticas florestais baseado no "Seguridad y Salud en el Trabajo 
Forestal - Repertório de Recomendações Práticas de la OIT", semelhante ao que ocorreu no Chile que teve a adoção de um Código de Práticas Florestais em 1997, após dois anos de intensivo trabalho de seis comissões técnicas, com o apoio da OIT. Em 1999, os comitês tripartites nacionais e regionais promoveram ações de treinamento do programa para implementação do referido Código, OIT (1999).

No Brasil, as discussões ocorreram com a participação de segmentos do governo, de trabalhadores e de empregadores em encontros e seminários promovidos pela Câmara de Desenvolvimento Sustentado da Amazônia, pela Sociedade Brasileira de Silvicultura - SBS, pela Central Única de Trabalhadores - CUT e pela FUNDACENTRO. Os debates sobre a possível criação de um código ocorreram devido a precariedade das condições de trabalho em algumas localidades do Brasil. Em 1997, a atividade florestal foi responsável por $4,11 \%$ dos 6.153 afastamentos registrados por invalidez permanente, em decorrência dos acidentes de trabalho, INSS (1997).

O Ministério do Trabalho e Emprego priorizou o ano de 2000 como sendo o ano da Agricultura, incluindo as atividades florestais, para as ações de regulamentação em segurança e saúde do trabalho rural. O Brasil participou da $88^{\text {a }}$ Conferência Internacional do Trabalho, realizada pela Organização Internacional do Trabalho - OIT em 2001, contribuindo para a elaboração da Convenção e Recomendação de Segurança e Saúde na Agricultura e iniciou o processo de revisão das Normas Regulamentadoras Rurais, abrangendo todas as atividades do setor primário, incluindo o setor de florestas, Yamashita (2001). 
A introdução do trabalho em turnos, especialmente o trabalho noturno na atividade florestal aliada às jornadas excessivas de trabalho, pode trazer riscos de acidentes e riscos à saúde do trabalhador. A interação do trabalho em turnos com outros fatores agressivos do trabalho, como a vibração de corpo inteiro a que o operador de máquinas está submetido, podem gerar efeitos deletérios sinérgicos. Segundo Grammel (1994), nos operadores de processadores, que comandam cerca de 45 a 50 diferentes elementos com cerca de 69 funções, foi detectado um aumento no desgaste emocional e mental em função da vibração da máquina, da grande necessidade de concentração, do trabalho sob pressão de tempo, da pouca movimentação física e do isolamento. Desta forma a pesquisa recomenda a redução na jornada de trabalho ou a alternância da jornada diária com outras funções.

A atividade de colheita florestal é realizada em ambiente de paisagem única, normalmente monoculturas de pinos e eucaliptos, não permitindo ao trabalhador ter noção do horizonte e da ocorrência de qualquer fato além daqueles circunscritos ao da realização de sua tarefa, tornando-se um trabalho solitário e monótono. Além disso, a condução e a operação de veículos requer um estado de atenção e de condições psicológicas adequadas que incluem nível inteligência, coordenação psicomotora e controle emocional para o bom desempenho do trabalho, sem risco à sua saúde e segurança e dos demais companheiros do trabalho.

Dentro deste panorama, o presente trabalho teve como objetivo avaliar as condições de trabalho do operador de máquinas na colheita florestal enfatizando os aspectos de segurança e ergonomia devido a crescente introdução de novas máquinas na colheita florestal. Teve como objetivos 
específicos avaliar a exposição do operador à vibração emitida pelas máquinas de colheita e discutir os potenciais efeitos da exposição a vibrações de corpo inteiro e o trabalho em turnos neste tipo de atividade, partindo do pressuposto de que a modernização do setor florestal com a introdução de novas tecnologias trouxe beneficios aos trabalhadores, mas trouxe também problemas a sua saúde e segurança antes desconhecidos, conforme podemos observar a citação de Grammel (1994) de que Com a transição do trabalho manual para os métodos moto-manuais, principalmente com a introdução dos sistemas altamente mecanizados, como, por exemplo, os "Harversters" semiautomatizados, diminuiu o esforço físico e aumentou o desgaste mental do trabalhador. Desta forma, também houve uma alteração nos métodos de avaliação deste esforço. Enquanto no passado o tema central era a medição do dispêndio energético, ou seja, a determinação da quantidade de kilocalorias por minuto, atualmente a carga mental de trabalho e o "stress"é que se tornaram importantes. Esforço mental, pressão psicológica e trabalho sob pressão alteram o tipo de desgaste dos trabalhadores... Fica evidente no caso dos "Harverters" (trabalho sob pressão, alta concentração, grande responsabilidade, trabalho isolado, pouca movimentação, etc.) o aparecimento de uma nova forma de esforço. 


\section{REVISÃO DE LITERATURA}

\subsection{Panorama do Setor Florestal no Mercado Brasileiro}

O setor de florestas plantadas no Brasil teve seu incremento no ano de 1966 com a lei de incentivo à preservação do meio ambiente, que possibilitou as empresas abaterem $50 \%$ do valor do imposto de renda devido, para aplicar em projetos de reflorestamento visando suprir o mercado de papel e celulose, em franca expansão no período, e o abastecimento das usinas siderúrgicas com o carvão vegetal. Os projetos de reflorestamento em conseqüência dessa política fiscal totalizaram 6,2 milhões de hectares no período de 1967 a 1986 (Leão, 2000).A cultura de interesse foi o gênero Eucalyptus por apresentar rápido crescimento e permitir cortes econômicos sucessivos, conforme podese verificar através das observações da SBS: "No setor de florestas plantadas o corte do eucalipto para industrialização ocorre aos 7 anos de idade, num regime que permite até 3 rotações sucessivas e econômicas, com ciclo de até 21 anos. Plantios clonais de hibridos de Eucalyptus produzem 45 m3/ha/ano".

A cultura do gênero Pinus também foi eleita por ter bom desenvolvimento em climas mais amenos e atender também ao setor de serrarias. O Pinus, plantado no Sul e Sudeste do Brasil, que, além de servir como matéria prima para produção de celulose, era utilizado para a fabricação de móveis, chapas e placas, estava sendo cortado com 20 a 25 anos, depois de 
passar por sucessivos desbastes. A produtividade atingia até $35 \mathrm{~m} 3 / \mathrm{ha} /$ ano (SBS, 2001).

O setor de florestas plantadas no Brasil conta atualmente com um total de 235 empresas de papel e celulose, com 268 unidades industriais em 17 Estados, sendo formada por empresas de celulose e papel, de carvão vegetal, de processamento mecânico de madeiras, de chapas e de compensados móveis e de produtos não madeireiros, contribuindo com US\$ 2 bilhões em impostos e participando com 4,0\% no PIB nacional, em 1999 (SBS, 1997).

O consumo brasileiro de madeira roliça em 1999 foi da ordem de 350 milhões de metros cúbicos de madeira roliça e no mercado interno o setor de base florestal gera receitas da ordem de US\$ 20 bilhões e oferece $700 \mathrm{mil}$ empregos diretos e 2 milhões indiretos. (SBS, 2000).

Atualmente as florestas plantadas apresentam uma área aproximada de 4,8 milhões de hectares de florestas de rápido crescimento, compostas principalmente por eucaliptos e pinus (Tabela. 1).

Tabela 1. Área total reflorestada no Brasil (ha) - 1999

\begin{tabular}{lccc}
\hline \multicolumn{1}{c}{ Estado } & Eucalipto & Pinus & Total \\
\hline Minas Gerais & 1.535 .290 & 143.410 & 1.678 .700 \\
São Paulo & 574.150 & 202.010 & 776.160 \\
Paraná & 67.000 & 605.130 & 672.130 \\
Santa Catarina & 41.550 & 318.120 & 359.670 \\
Bahia & 213.400 & 238.390 & 451.790 \\
Rio Grande do Sul & 115.900 & 136.800 & 252.700 \\
Outros & 418.590 & 196.190 & 614.780 \\
Total & 2.965 .880 & 1.840 .050 & 4.805 .930 \\
\hline
\end{tabular}

Fonte: SBS, 2000 
Os principais segmentos da indústria de base florestal no Brasil são hoje a de celulose e papel, a de madeira sólida (madeira serrada, fabricação de painéis e móveis) e a de carvão vegetal e lenha para fins industriais. Há ainda, outras finalidades com significado econômico regional como a resinagem (Sudoeste), a borracha natural, a castanha-do-pará, o babaçu (Norte) e a erva mate (Sul). A floresta pode oferecer outros derivados com valor econômico direto e benefícios sociais, pouco explorados no país, tais como: madeira para construção civil, para a construção de ferramentas e para embalagens. Como recursos indiretos temos a produção de mel, a criação de animais silvestres e de gado em algumas áreas de reflorestamento (Leão, 2000).

O Brasil exportou, através do setor florestal, cerca de US\$ 3,5 bilhões em 1999 (Tabela. 2), com uma participação equivalente a 7,0\% das exportações nacionais, sendo que a celulose de eucalipto é o produto de base florestal que representa a participação mais expressiva no mercado mundial com 5,2\% dos negócios internacionais (SBS, 2000)

Tabela 2. Produção de base florestal no Brasil - 1999

\begin{tabular}{lcr}
\hline \multicolumn{1}{c}{ Produto } & Quantidade (mil toneladas) & \multicolumn{1}{c}{$\begin{array}{c}\text { US } \$ \\
\mathbf{( 1 0 0 0 )}\end{array}$} \\
\hline Celulose & 3.111 & 1.243 .628 \\
Papel & 1.330 & 900.758 \\
Madeira Serrada & 920 & 411.000 \\
Madeira Compensada & 379 & 264.265 \\
Madeira Laminada & 125 & 96.777 \\
Borracha & 136 & 121.744 \\
Carvão Vegetal & 9,1 & 1.988 \\
Painéis de Fibra & 205 & 75.642 \\
Outros & 1.778 & 386.080 \\
& & \\
Total & $7.993,1$ & 3.501 .882 \\
\hline
\end{tabular}

Fonte: SBS, 2000 


\subsection{PANORAMA DOS ACIDENTES DO TRABALHO.}

\subsubsection{Acidentes e doenças do trabalho no mundo}

A população mundial que trabalha na agricultura corresponde a $50 \%$ do total da população ativa mundial e estima-se que o número de trabalhadores que participam da produção agrícola é de 1,3 bilhão, incluídas as atividades agrícolas, pecuária, silvicultura e exploração florestal. A força de trabalho na agricultura representa $10 \%$ da população economicamente ativa nos países desenvolvidos e 59\% nos países menos desenvolvidos, OIT (1999).

Estima-se que no mundo são empregadas centenas de milhões de pessoas em condições de trabalho inseguro ou gerando doenças decorrentes do trabalho e que, a cada ano, as doenças relacionadas ao trabalho são responsáveis por 1,1 milhão de mortes, o que corresponde ao número igual de mortes por malária no mundo; este quadro inclui cerca de 300.000 fatalidades dos 250 milhões de acidentes que ocorrem no local de trabalho anualmente, e que levam a incapacidade parcial ou completa para o trabalho, de acordo com dados da Organização Mundial da Saúde, OMS (2000).

Segundo as estimativas da OIT, 1997, do total de 330.000 acidentes do trabalho fatais em todo o mundo, pelo menos 170.000 vítimas foram trabalhadores agrícolas. $\mathrm{O}$ aumento do uso de máquinas, implementos e produtos químicos na agricultura, têm aumentado os riscos de acidentes e, em alguns países, a taxa de acidentes fatais na agricultura tem sido o dobro do que em outros setores. 
Calcula-se que, anualmente, ocorram 160 milhões de novos casos de doenças relacionadas ao trabalho no mundo, como: doenças cardiovasculares e respiratórias, câncer, perda auditiva, desordens músculo - esqueléticas e reprodutivas, doenças mentais e neurológicas.

Segundo a OMS (2000), aproximadamente $30 \%$ da força de trabalho nos países desenvolvidos e entre 50 a $70 \%$ em países em desenvolvimento, podem estar expostos à carga de trabalho física e mental ou a condições de trabalho ergonomicamente deficientes. Os trabalhos mais afetados são nos setores da mineração, da agricultura, da pesca, da construção civil, da saúde, do setor madeireiro e de armazéns.

$\mathrm{O}$ estresse no trabalho tem sido associado com doenças cardiovasculares, particularmente hipertensão e distúrbios mentais. O estresse no trabalho pode ser provocado por condições sociais precárias no trabalho e estilo de administração baseado na exclusão dos trabalhadores do processo de decisão na organização do trabalho.

Em países menos desenvolvidos são encontrados problemas de higiene ocupacional, essencialmente na agricultura e outras atividades de produção primária. A carga física de trabalho freqüentemente combinada com exposição ao calor, a agrotóxicos e a poeiras orgânicas, é agravada pelos fatores não ocupacionais como as doenças parasitárias e infecciosas crônicas. As más condições sanitárias e de higiene, problemas nutricionais, pobreza e ignorância tem elevado o risco de injúrias e doenças profissionais.

As mulheres têm contribuído no aumento da força de trabalho nos setores da agricultura, indústria e serviços, compondo aproximadamente $42 \%$ da população global ativa. Nas tarefas executadas as mulheres estão sujeitas a 
doenças músculo-esqueléticas, porque nenhum dos trabalhos, equipamentos e ferramentas, normalmente projetados para o homem, são adaptados à sua constituição e fisiologia, OMS (2000). No setor florestal é intensa participação das mulheres nas atividades de viveiro e em algumas empregam mulheres para a operação de máquinas de colheita.

A Organização Internacional do Trabalho estima que em 1997, a economia mundial perdeu aproximadamente $4 \%$ do produto interno bruto devido às doenças e injúrias relacionadas ao trabalho, mostrando que o estado de saúde dos trabalhadores tem impacto imediato e direto nas economias mundiais e que a melhoria das condições de trabalho é um investimento com alto impacto econômico.

Segundo Petterson ${ }^{1}$, citado por Fenner (1991), o trabalho florestal na Suíça não é mais uma das atividades com as mais altas taxas de acidentes, pois da década de 1970 ao início dos anos 80, foi possível reduzir em 50\% a incidência de acidentes conjuntamente com o decréscimo do coeficiente de gravidade dos acidentes. Os principais fatores responsáveis por esta redução foram: a melhoria da tecnologia de produção, a nova estrutura de salários, os melhores equipamentos de proteção; a mecanização das operações florestais, a melhoria das condições de segurança e saúde com o treinamento dos trabalhadores e supervisores e o conseqüente aumento da consciência dos problemas de segurança, além do desenvolvimento de trabalhos de pesquisa e desenvolvimento para a redução de acidentes.

As máquinas e outros equipamentos de uso agrícola e florestal também são responsáveis por diversos acidentes e doenças, entre eles a exposição a

\footnotetext{
${ }^{1}$ Fenner, P.T. Estudo Descritivo dos Acidentes de Trabalho em uma Empresa Florestal, 1991
} 
níveis de vibração e de ruído acima dos recomendáveis, acidentes por tombamento e capotamento de máquinas e acidentes provocados pelas partes móveis das engrenagens. No Missouri, EUA, observou-se que 16,8\% dos agricultores entre 25 e 64 anos de idade apresentavam perda auditiva suficiente para interferir com a comunicação verbal. Na Austrália 70\% das mortes ocorridas por acidentes do trabalho na agricultura entre 1982 e 84 foram ocasionadas por equipamentos mecânicos móveis, sendo que $40 \%$ delas provocadas por tratores ou implementos por eles conduzidos. Os dados dos EUA apontam o trator como responsável por 40 a $60 \%$ dos acidentes e fatalidades na agricultura. Em 1989, houve 7,2 óbitos por 100.000 tratores, sendo que o tombamento e capotamento contribuíram com $55 \%$ de todas as fatalidades (Garcia, 2000).

Embora o meio rural geralmente seja identificado como um ambiente bucólico e pacífico, o trabalho rural tem sido descrito como uma das mais estressantes ocupações, por ser realizado sob condições adversas de tempo, por sua natureza perigosa, pelo isolamento, pela carga e jornada de trabalho e pela sua vulnerabilidade econômica. O pouco controle dos agricultores sobre a instabilidade de preços dos produtos agrícolas e a sua vulnerabilidade às condições ambientais que interferem na produção e no custo dos seus produtos são fatores que levam à depressão e a ansiedade. (Garcia, 2000). 


\subsection{Acidentes do trabalho no Brasil}

O Brasil, quando da promulgação da Constituição de 1988, declarou igualdade de direitos sociais para os trabalhadores urbanos e rurais. Amparados pela Constituição e pelas Convenções e Recomendações de organizações internacionais que o país ratifica, os trabalhadores rurais têm garantido seus direitos a boas condições de trabalho e à saúde. Porém, o cenário brasileiro no setor agrícola e florestal ainda apresenta sérias dificuldades que são emergencialmente prioritárias em relação aos problemas de segurança e de saúde no trabalho.

Em 1997, havia 54 milhões de pobres no Brasil, ou seja, 34\% dos habitantes do país, dos quais 24 milhões indigentes, considerados abaixo do nível da pobreza (Lahóz, 1999). De acordo com a Tabela 3, pode-se observar que $36 \%$ dos pobres encontram-se na área rural.

Tabela 3. Distribuição dos pobres no Brasil, 1997.

\begin{tabular}{lc}
\hline Regiões & \% pobres \\
\hline Centro das regiões metropolitanas & 9 \\
Periferia das regiões metropolitanas & 9 \\
Outras grandes cidades & 13 \\
Cidades médias & 14 \\
Cidades pequenas & 20 \\
Área Rural & $\mathbf{3 6}$ \\
\hline
\end{tabular}

Fonte: modificado de Lahóz, 1999.

A instabilidade econômica esteve presente no Brasil durante muito tempo até que em 1986, quando da implantação do plano econômico denominado Plano Cruzado, houve uma estabilização da economia, com uma 
queda no índice de pobreza: de 65 milhões de pobres em 1984, para 41,5 milhões em 1986. Com o fracasso do plano e o retorno da inflação, o número de pobres voltou praticamente aos mesmos níveis do início da década. Com o Plano real, atualmente em vigor, o número de pobres voltou a diminuir em cerca de 10 milhões e vem se mantendo estável, segundo dados do Instituto de Pesquisa Econômica Aplicada (Lahóz, 1999).

O Brasil atualmente tem índices de urbanização semelhante aos dos países avançados e até os supera em alguns casos, ele é de aproximadamente $75 \%$ e chega a $93 \%$ em algumas regiões, como acontece no Estado de São Paulo (Sayad, 2000). No entanto, parte da população urbana tem ocupação rural. A distribuição da população rural e urbana no Brasil em 1996, é mostrada na Tabela 4.

Tabela 4. Distribuição da população rural e urbana pelas regiões do Brasil, em 1996.

\begin{tabular}{|c|c|c|c|c|c|c|c|}
\hline \multirow[t]{2}{*}{ Regiões } & \multirow{2}{*}{$\begin{array}{c}\text { População } \\
\text { Total } \\
\text { (1000 Hab.) } \\
\text { [A] }\end{array}$} & \multicolumn{2}{|c|}{$\begin{array}{c}\text { População } \\
\text { Urbana } \\
{[\text { B] }}\end{array}$} & \multirow{2}{*}{$\begin{array}{c}\text { Proporção } \\
\text { População } \\
\text { Urbana } \\
(\%) \\
{[\mathbf{B} / \mathbf{A}]}\end{array}$} & \multicolumn{2}{|c|}{$\begin{array}{c}\text { População } \\
\text { Rural } \\
\text { [C] }\end{array}$} & \multirow{2}{*}{$\begin{array}{c}\text { Proporção } \\
\text { População } \\
\text { Rural (\%) } \\
\text { [C/A] }\end{array}$} \\
\hline & & $\begin{array}{l}1000 \\
\text { hab. }\end{array}$ & $\%$ & & $\begin{array}{l}1000 \\
\text { hab. }\end{array}$ & $\%$ & \\
\hline Norte & 11288 & 7039 & 5,7 & 62,4 & 4249 & 12,5 & 37,6 \\
\hline Nordeste & & 29198 & 23,7 & 65 & 15569 & 45,6 & 34,8 \\
\hline Centro-Oeste & 10501 & 8865 & 7,2 & 84,4 & 1636 & 4,8 & 15,6 \\
\hline Sudeste & 6700 & 59709 & 48,6 & 89,1 & 7292 & 21,4 & 10,9 \\
\hline Sul & 23514 & 18157 & 14,8 & 77,2 & 5357 & 15,7 & 22,8 \\
\hline Total Brasil & 157071 & 122968 & 100,0 & 78,3 & 34102 & 100,0 & 21,7 \\
\hline
\end{tabular}

Fonte: IBGE, 1998, modificado por Alves Filho, $1999 .$.

No Brasil, a tecnologia deu condições para a agricultura expandir sua produção, porém não houve como nos países industrializados, uma política para proteger os efeitos do desemprego e preservar a renda do setor. A 
tecnologia mecânica aumenta a velocidade do êxodo rural, substituindo o trabalhador assalariado e os que produzem em regime famílias, Alves Filho (1999).

É importante observar que o número de pessoas ocupadas na atividade agrícola representava $24,5 \%$ da população total ocupada no país em 1996 , ou seja, quase 18 milhões de trabalhadores, representando um número $23 \%$ maior do que, por exemplo, o total de pessoas ocupadas nas atividades industriais, conforme mostra a Tabela 5 (IBGE, 1998 e Prado, 1999).

Tabela 5. Distribuição das pessoas ocupadas, de 10 anos ou mais de idade, por ramo de atividade econômica da ocupação principal, Brasil, 1996. Pessoas Ocupadas*

\begin{tabular}{ll}
\multicolumn{1}{c}{ Ramo de Atividade Econômica } & $(\%)$ \\
\hline Agrícola & 24,5 \\
Indústria de transformação, construção e outras & 19,9 \\
Comércio de mercadorias & 13,1 \\
Serviços** & 42,5
\end{tabular}

* número absoluto: 68040206;

** incluí: prestação de serviços, serviços auxiliares da atividade econômica, serviço social, administração pública, transporte e comunicação e outras atividades;

Fontes: IBGE, 1998, modificado por Alves Filho, 1999.

"A agroindústria se articula para frente com a indústria de embalagens e com o processamento agroindustrial (cada vez mais sofisticado) e, para trás, com a indústria de insumos (pesticidas, fertilizantes, rações, insumos veterinários) e de equipamentos para a agricultura. Numa perspectiva ampla, inclui desde setores de processamento básico (adicionando valor na secagem, no beneficiamento e na embalagem) até segmentos que envolvem o processamento de matéria-prima agricola, mas que são costumeiramente identificados como tipicamente industriais: setor têxtil, de calçados e de papel 
e celulose. Estes possuem caracteristicas estruturais distintas dos demais, devendo ser tratados, cada um, como cadeias próprias e com considerável grau de autonomia. A agroindústria inclui ainda a produção de energia a partir da biomassa, área em que o Brasil é líder mundial. Estima-se que na conceituação ampliada, a agroindústria represente mais de 30\% da economia brasileira. E, certamente, está nela a maior parte dos setores econômicos em que o Brasil detém competitividade internacional'.'(Sayad, 2000)

As más condições sociais e econômicas que, de modo geral, predominam no setor rural e considerando o número expressivo de pessoas que trabalham na agricultura, faz-nos que devamos ter uma situação mais crítica em relação ao número e a gravidade de ocorrência de doenças e acidentes do trabalho. Se as más condições de trabalho podem ser facilmente identificadas nos setores secundário e terciário, para os quais se deslocam os maiores investimentos econômicos, piores devem ser as condições do setor primário.

O registro oficial dos acidentes de trabalho no Brasil é feito exclusivamente através da Comunicação de Acidente do Trabalho - (CAT), que se aplica somente a trabalhadores segurados pelo Instituto Nacional de Seguridade Social - INSS, que representam um pouco mais de um terço do total da população ocupada no Brasil e inclui um número bastante reduzido de trabalhadores rurais, o que pode ser observado na Tabela 6 , além de excluir das estatísticas, os trabalhadores da economia informal e o autônomos. 
Tabela 6. Pessoas ocupadas e trabalhadores registrados pelo Instituto Nacional de Seguridade Social - INSS, Brasil, 1996.

\begin{tabular}{lcc}
\hline \multicolumn{1}{c}{ Ramo de atividade } & $\begin{array}{c}\text { Pessoas } \\
\text { ocupadas }\end{array}$ & $\begin{array}{c}\text { Trabalhadores registrados } \\
\text { pelo INSS }\end{array}$ \\
\hline $\begin{array}{l}\text { Brasil (todos os ramos de } \\
\text { atividades econômicas) }\end{array}$ & 68.040 .206 & 24.311 .448 \\
Atividade agrícola & 17.930 .728 & 1.000 .000 (aproximado) \\
\hline
\end{tabular}

Fontes: IBGE, 1998, modificado por Alves Filho, 1999

Em pequenas propriedades a situação é mais grave; se o trabalhador é considerado inapto durante a recuperação de um acidente, o dono da propriedade recebe uma indenização durante três meses, o que pode ser insuficiente para pagar outro trabalhador para suprir a ausência do acidentado. Se o afastamento for por invalidez permanente, o trabalhador passa a receber um salário mínimo mensal.

Assim, os acidentes decorrentes do trabalho, além dos danos provocados ao trabalhador, oneram os cofres da Previdência com o pagamento de indenizações, de benefícios e de tratamento de reabilitação profissional. Somam-se ainda, os custos das empresas ao substituir o trabalhador durante o período de afastamento para a sua reabilitação.

De acordo com o INSS, em 1996 foram registrados 395.455 acidentes, que podem ser classificados conforme a tabela 7 . 
Tabela 7. Acidentes registrados pelo INSS em 1996.

\begin{tabular}{lc}
\hline \multicolumn{1}{c}{ Tipo de acidente } & Quantidade \\
\hline Típico & 325.870 \\
Trajeto & 34.696 \\
Doença do trabalho & 34.889 \\
Total de acidentes registrados & 395.455 \\
\hline
\end{tabular}

Fonte: Ministério da Previdência Social, 2000.

$\mathrm{Na}$ Tabela 8, podemos verificar os acidentes do trabalho ocorridos na agricultura, pecuária, silvicultura e exploração florestal, conforme os dados das estatísticas do INSS de 97, para cada grupo de 100 mil acidentes.

Tabela 8. Distribuição da freqüência e do coefíciente ${ }^{1}$ dos acidentes fatais $^{2} \mathrm{em}$ decorrência de acidentes de trabalho no Brasil, segundo as classes de atividades econômicas, 1997.

\begin{tabular}{lcr}
\hline \multicolumn{1}{c}{ Classes de atividades econômicas } & Freqüência & Coeficiente \\
\hline $\begin{array}{l}\text { Agricultura, pecuária, silvicultura e } \\
\text { exploração florestal }\end{array}$ & 196 & 19,56 \\
Total & & \\
\hline
\end{tabular}

Fonte dos dados brutos: MPAS/INSS e MTE/RAIS-97

(1) Coeficiente calculado sobre o número de trabalhadores na classe

(2) Pensão por morte por acidente de trabalho (B93)

(3) CNAE/IBGE

Elaboração MTE/Departamento de Segurança e Saúde no Trabalho

Do ponto de vista de leis, regulamentos específicos e de dispositivos complementares estaduais e municipais estão amparados os trabalhos com o uso de agrotóxicos; a proteção do trabalhador com uso de equipamentos de 
proteção individual; o direito a serviços médicos de saúde e de segurança e a obrigatoriedade da instituição de comissões internas de prevenção de acidentes.

Os riscos decorrentes da exposição a agentes físicos e mecânicos na agricultura não estão contemplados em leis específicas, especialmente, quanto à comercialização de produtos perigosos e insalubres, ficando a cargo da lei do consumidor, os casos de produtos que não atendam os requisitos mínimos de segurança. Os casos de acidentes ou doenças decorrentes do uso desses insumos são julgados a posteriori fazendo-se uma analogia com a lei aplicável ao setor urbano e a Constituição Nacional.

A preocupação com aspectos de segurança e ergonomia na maquinaria agrícola passou a ser maior por volta dos anos 80 , quando se começaram as avaliações através de ensaios realizados por institutos de pesquisa. Alguns modelos de tratores agrícolas passaram, então, a incorporar as recomendações sugeridas nos relatórios de avaliação, como proteção para a tomada de potência, para o eixo cardam, melhoria da visibilidade, entre outros.(Yamashita, 2000).

O conhecimento do sistema homem-máquina para aplicação dos princípios ergonômicos é de fundamental importância, pois é meta fundamental da ergonomia a preservação da integridade física, mental e social do ser humano. Um indivíduo ao operar uma máquina deve transformar as informações recebidas em ações de comando, sem prejudicar a sua saúde e segurança. Como o fator humano é o principal componente que determina a produtividade, bem como o sucesso ou o fracasso de um sistema de trabalho, é necessário, portanto, adaptar a máquina de forma mais adequada possível às 
características humanas, para a redução do erro, do cansaço e da ocorrência do acidente de trabalho, Minette (1996).

Atualmente, a conscientização das empresas para aspectos de qualidade no processo de fabricação, frente aos requisitos das normas ISO 9000 e de preservação do ambiente das normas ISO 14000, abre perspectiva para que os aspectos de segurança e de ergonomia sejam melhores observados e perseguidos.

O aumento da produção e da produtividade e a busca da preconizada sustentabilidade da produção agrícola não podem prescindir de estratégias para lidar com a segurança e a saúde no trabalho rural, Garcia (2000).

Atualmente, as normas e regulamentos rurais, que abrangem também o setor florestal, encontram-se em revisão, já foram colocados em consulta pública e estão em discussão através da negociação tripartite (discussão entre representações de governo, empregadores e trabalhadores).

\subsection{Efeitos à saúde pela exposição à vibração}

Diversos trabalhos sobre os efeitos no corpo humano pela exposição à vibração de corpo inteiro no uso de tratores agrícolas são mostrados a seguir, levantando a preocupação de alguns pesquisadores com a introdução crescente da modernização no setor florestal.

A influência da vibração de baixa freqüência sobre os operadores de tratores agrícolas pode provocar problemas musculares e respiratórios, problemas na coluna vertebral e de contração dos músculos abdominais. Em conseqüência disso, recomenda-se que as mulheres não operem máquinas nos 
períodos de menstruação, pois tal condição pode provocar o congestionamento da região pélvica. A vibração afeta também o sistema nervoso autônomo, podendo provocar fadiga e irritabilidade, Collette, (1973);

Os tratores agrícolas também apresentam ressonância de $3 \mathrm{~Hz} \mathrm{a} 8 \mathrm{~Hz}$, o que coincide com a zona intolerável máxima do corpo humano, Collette (1973).

A exposição à vibração de corpo inteiro pode provocar problemas músculo-esqueléticos, atingindo especialmente as regiões do pescoço e ombro devido ao trabalho estático e repetitivo. Quando em condições de trabalho prolongado pode conduzir à fadiga, estendendo os problemas músculoesqueléticos às regiões dos braços e coluna cervical. A taxa de batimento cardíaco e consumo de oxigênio podem ser afetados, Gallis (1997).

Os efeitos da vibração no corpo vão desde uma ligeira sensação de náusea até graves problemas físicos como espasmo vascular, dores nas costas, pescoço, peito, estômago, cãimbras, dificuldade respiratória, ressonância em várias partes do corpo que tem como principais conseqüências o desconforto físico e psicológico, lesões, cansaço e queda na produtividade, FAO( 1993).

De acordo com a FAO (1993), as vibrações de alta freqüência podem causar problemas severos à saúde que podem ser agrupados como: mal-estar físico ou psicológico; alterações das capacidades funcionais; lesões reversíveis ou irreversíveis e ainda podem determinar cansaço e baixo rendimento no trabalho. A natureza e a magnitude dos efeitos dependem principalmente da freqüência, da intensidade e direção das vibrações; da duração da exposição; da postura e da parte do corpo em contato com a fonte de vibração. 
As vibrações de corpo inteiro podem afetar uma pessoa em pé sobre uma base que está recebendo vibração ou sentada como, por exemplo, ao dirigir um trator. As vibrações entre as freqüências de 1 a $20 \mathrm{~Hz}$ são particularmente mais incômodas e cansativas e estas são as freqüências que predominam nos veículos e na indústria. Nas atividades florestais, os operadores de máquinas queixam-se muito de dores nas costas e no pescoço relacionadas com as vibrações de corpo inteiro. Outras queixas comuns são dores no peito e no estômago, câimbras musculares e dificuldades respiratórias FAO (1992).

As vibrações que atingem o corpo inteiro podem afetar, também, o sistema nervoso central e podem dificultar os processos metabólicos e aumentar as perdas de energia. Níveis elevados de vibração podem afetar os órgãos internos, inclusive a visão.

Cada massa reage à vibração de maneira diferente, dependendo da atenuação ou amplificação da mesma devido ao fenômeno de ressonância que pode provocar o estiramento ou compressão dos órgãos. As vibrações de componentes verticais ou horizontais possuem efeitos diferenciados, no primeiro caso a ressonância entre 3 e $5 \mathrm{~Hz}$ é a ressonância que aparece dentro do sistema torácico-abdominal, com conseqüência de risco de estiramento na região da coluna vertebral (sobretudo na articulação dorso lombar), de compressão axial de torção e de estiramento das vísceras. As vibrações horizontais até $6 \mathrm{~Hz}$ são menos toleráveis e entram em ressonância nas regiões cervical, dorso-lombar e das mãos, Iguti (1989). 
Segundo Santos et al. (1997), as vibrações de corpo inteiro dependendo da freqüência podem afetar diferentes funções, conforme pode ser observado na Tabela 9:

Tabela 9. Sintomas de exposição à vibração de corpo inteiro nas diferentes freqüências.

\begin{tabular}{|c|c|}
\hline Freqüência & Sensações provocadas \\
\hline 2 a $15 \mathrm{~Hz}$ & Dores toráxicas, dificuldades respiratórias \\
\hline 2 a $20 \mathrm{~Hz}$ & Dores abdominais, problemas digestivos \\
\hline 4 a $10 \mathrm{~Hz}$ & Dores de cabeça \\
\hline 5 a $30 \mathrm{~Hz}$ & $\begin{array}{l}\text { Problemas visuais (perturbações do movimento dos olhos, } \\
\text { baixa da acuidade visual) }\end{array}$ \\
\hline 4 a $300 \mathrm{~Hz}$ & Formigamento nos dedos \\
\hline
\end{tabular}

Cunha (2000), apresentou um modelo de programa de prevenção contra os prejuízos causados pela vibração, conforme Figura 1:

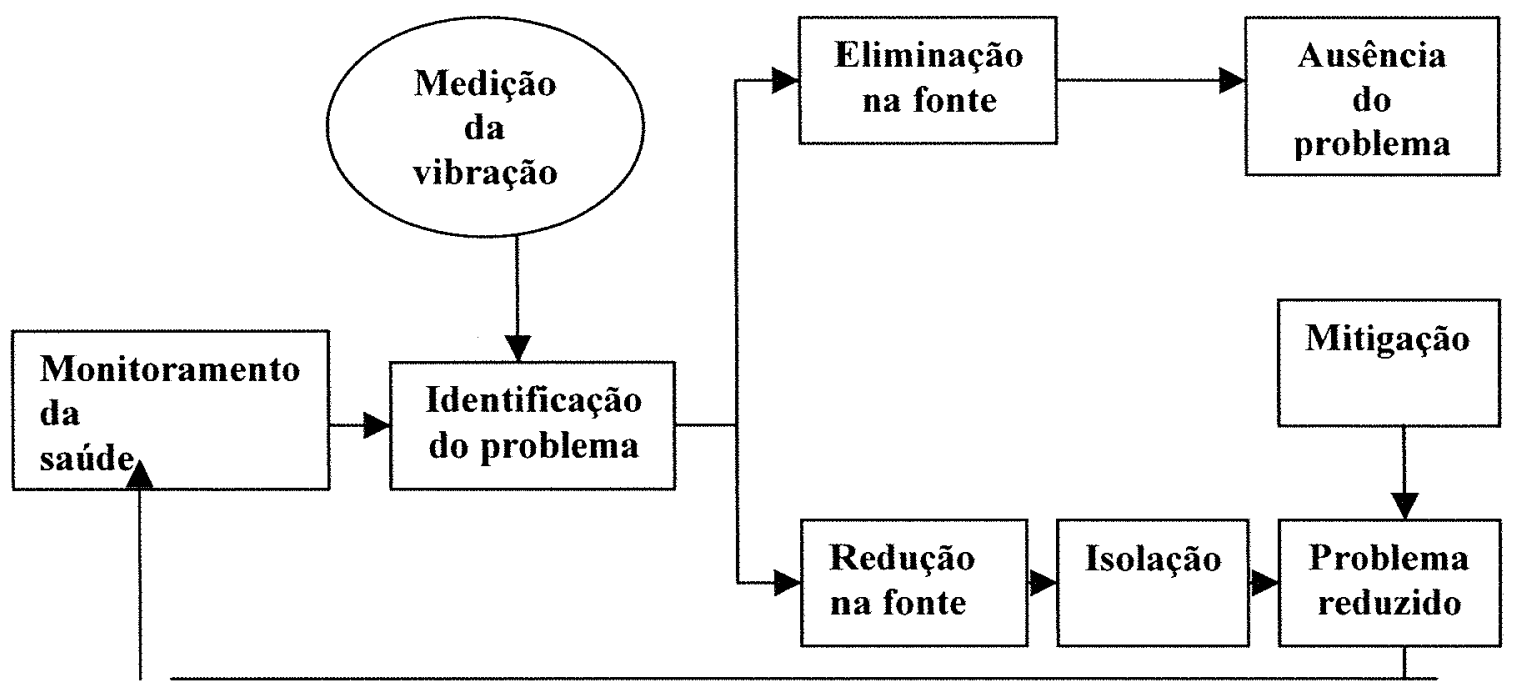

Figura 1- Esboço conceitual de um programa para prevenção de distúrbios ocasioandos pela vibração. 


\subsection{Efeitos à saúde ocasionados pelo trabalho em turnos}

A introdução da organização de trabalho semelhante a do setor urbano na área rural, no Brasil, fez com que muitas empresas presentes na região Sudeste venham adotando o trabalho em turnos, apesar da observação (FAO, 1993) de que o trabalho noturno ou em turnos é muito raro em operações florestais.

Devido à necessidade de otimização do sistema de colheita, com o uso de modernas máquinas de custo elevado, e a necessidade de alimentação constante das indústrias de papel e celulose, é comum no setor florestal o trabalho em turnos, em especial nas tarefas relacionadas com a colheita.

Alguns estudos foram realizados para determinar os efeitos do trabalho em turnos na atividade florestal, bem como para determinar o melhor tipo de turno a ser aplicado objetivando a redução dos efeitos à saúde e o aumento da produtividade.

O trabalho em turnos, especialmente o noturno, tem acarretado problemas de sono, distúrbios nervosos e digestivos nos trabalhadores. Os trabalhadores em turnos dormem menos horas do que aqueles que executam tarefas diurnas, apresentando cochilos mais longos e em maior número, apresentam sono descontínuo fora do período principal do sono e prejuízo do sono paradoxal.

Os horários irregulares de refeições e dietas mal equilibradas levam os trabalhadores a ter problemas digestivos, com modificação do ritmo biológico de secreção gástrica, Fischer ( 1980). 
As condições de habitação e os ruídos diurnos (barulho de crianças, trafego de carro etc.) são fatores que influenciam na má qualidade do sono diurno, Fischer (1980) e FAO (1993).

O trabalho noturno pode provocar a sensação de inquietação, pois o sono diurno, o mais curto do dia, pode provocar a deficiência de sono acumulada, trazendo doenças como úlceras, distúrbios nervosos, problemas no estômago, intestino e fadiga crônica. O trabalho noturno e o trabalho por turnos devem ser evitados, sempre que possíveis, fazendo-se um grande esforço para minimizar as desvantagens que eles impõem ao trabalhador.

O trabalho noturno na atividade florestal pode levar a dores de cabeça, a pontadas nos olhos, ao estresse e a posturas desconfortáveis pela má visibilidade, FAO (1993).

O organismo humano é físiologicamente distinto nos diferentes horários diurnos e noturnos. Suas funções biológicas apresentam ritmos circadianos definidos geneticamente que são governados por osciladores internos endógenos. Sob uma rotina diurna estes ritmos estão sincronizados para permitir que as pessoas estejam física e mentalmente ativas durante o dia e durmam à noite, Fischer (1991).

Segundo Wisner (1988), o trabalho noturno provoca efeitos desfavoráveis e os transtornos no sono são mais marcados. O sono noturno é o único que permite sobrepor uma duração de sono médio de 6 horas por dia para o conjunto da população de trabalhadores. Os prejuízos causados pela desordem do sono são crescentes na medida em que a idade avança, devido a redução da duração do sono paradoxal. (figura2). 
Ïndice de Saúde

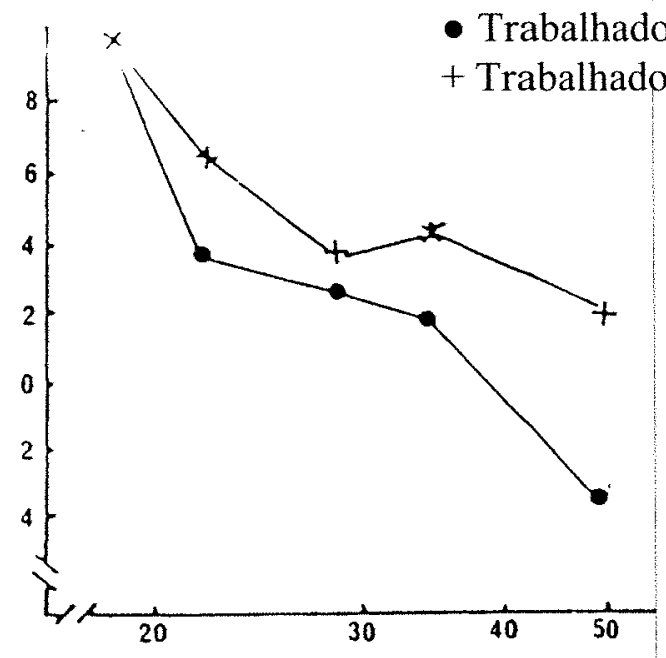

Figura 2..- Deterioração da saúde com a idade dos trabalhadores por turnos e trabalhadores diurnos.

Todo trabalho em horários alternantes altera nossa vida social e, em parte, também nossas funções biológicas; isto não significa necessariamente que a pessoa vá ficar doente, mas é uma ameaça para a sua saúde. Os distúrbios dos ritmos biológicos são as causas de grande parte do desgaste individual dos trabalhadores em turnos e podem prejudicar seu rendimento, saúde e bem-estar, assim como sua vida familiar e social, Rutenfranz e col. (1989);

O homem é um ser tridimensional, biológico, social e racional. Sob este ponto de vista, não pode haver humanização sem que todas estas dimensões sejam consideradas, Fiates \& Santos (1996). 


\subsection{Influência das características individuais no desempenho do trabalho}

O surgimento da mecanização e da automação para aliviar a carga de trabalho e o desdobramento das tarefas, resultou em uma sobrecarga física e mental do trabalhador pelo não aproveitamento do seu potencial humano para a elaboração e a realização das tarefas, que na maioria das vezes levam ao estresse no trabalho provocado pela monotonia no trabalho.

O processamento de informação em um "sistema homem-máquina" depende da interação de alguns fatores como a percepção, a interpretação e a elaboração mental das informações fornecidas pelos órgãos dos sentidos. A elaboração baseia-se no relacionamento das informações com o conhecimento (Grandjean).

Desta forma, a carga mental é influenciada pelo grau de vigilância no trabalho e pela tomada de decisões, que dependem do bem estar físico e psicológico do indivíduo.

A monotonia no trabalho também é influenciada pelo tipo de tarefa e pelo número de repetições no desenvolvimento do trabalho; pelo distanciamento e isolamento entre pessoas nos locais de trabalho e podem levar ao estresse.

Segundo Laville (1977), o nível de vigília sobre a tarefa a ser executada depende não só das características da tarefa, ou seja, da intensidade e freqüência dos estímulos do meio ambiente e dos sinais úteis, mas também do estado interno do operador, que varia em função de inúmeros fatores como hora do dia, período digestivo, falta de sono, entre outros. Em situações monótonas, por exemplo, em que os acontecimentos são raros, a atividade 
física é pequena, o operador permanece isolado e a tarefa é de longa duração, o nível de vigilância é elevado no início, cai rapidamente dos dez aos trinta minutos iniciais, caindo ainda mais após esse período.

Alguns fatores acentuam o decréscimo de vigilância, como ambientes quentes, o trabalho noturno e a falta de sono. Outros atenuam essa evolução como: diferença de contraste de forma e de cor entre sinais visuais e o fundo, diferença de freqüência e intensidade de sinais sonoros e o ruído de fundo. É importante observar que as pausas e mudanças de atividades restabelecem o nível inicial de vigilância e a dupla vigilância diminui a probabilidade de erros e omissões.

Outras características individuais influenciam no grau de comprometimento da saúde em decorrência do tipo de tarefa executada. Testes psicológicos associados a entrevistas são capazes de fornecer indicadores sobre algumas características individuais que influenciam a capacidade de desempenho para as atividades, Anastasi ( 1975) 


\section{MATERIAL E MÉTODOS}

\subsection{MATERIAL}

\subsubsection{Local de realização de ensaios}

As observações da situação de trabalho na colheita florestal e as avaliações de exposição à vibração foram realizadas em uma empresa de reflorestamento, localizada no interior de São Paulo. Trata-se de uma empresa com áreas reflorestadas em três estados do país, num total de 10.8845 ha, tendo aproximadamente $21 \%$ do total com matas nativas. Atualmente conta com um total de 718 empregados próprios e 32 empregados terceirizados.

A unidade onde foram realizadas as atividades de campo, faz o acompanhamento da eficiência e otimização dos sistemas de exploração florestal, considerando os estudos técnicos de segurança e ergonomia, realizados pelos próprios técnicos da empresa e também em parceria com as Universidades.

Avaliação foi realizada em solo suave ondulado, que facilita o trabalho mecanizado. 


\subsubsection{Instrumental utilizado para medição da vibração:}

Medidor de vibração marca Brüel \&Kjaer, tipo 2512;

Cabos para conexão marca Brüel \&Kjaer;

Calibrador para vibrações marca Brüel \&Kjaer tipo 4294;

Acelerômetro triaxial para vibrações de corpo inteiro marca Brüel \& Kjaer, tipo 4322;

Acelerômetro para vibrações de corpo inteiro marca Brüel \&Kjaer, tipo 4384; Obs.: O medidor de vibração foi calibrado antes e depois de cada etapa de medição.

\subsection{MÉTODOS}

A avaliação da exposição à vibração de corpo inteiro foi realizada com base na norma ISO 2631-1:1985.

O acelerômetro tipo 4322 foi fixado junto aos assentos dos operadores nos equipamentos avaliados (Figura 4) no ponto de transferência da vibração 3ao corpo, conforme os eixos de referências estabelecidas pela norma ISO $2631 / 85$. 


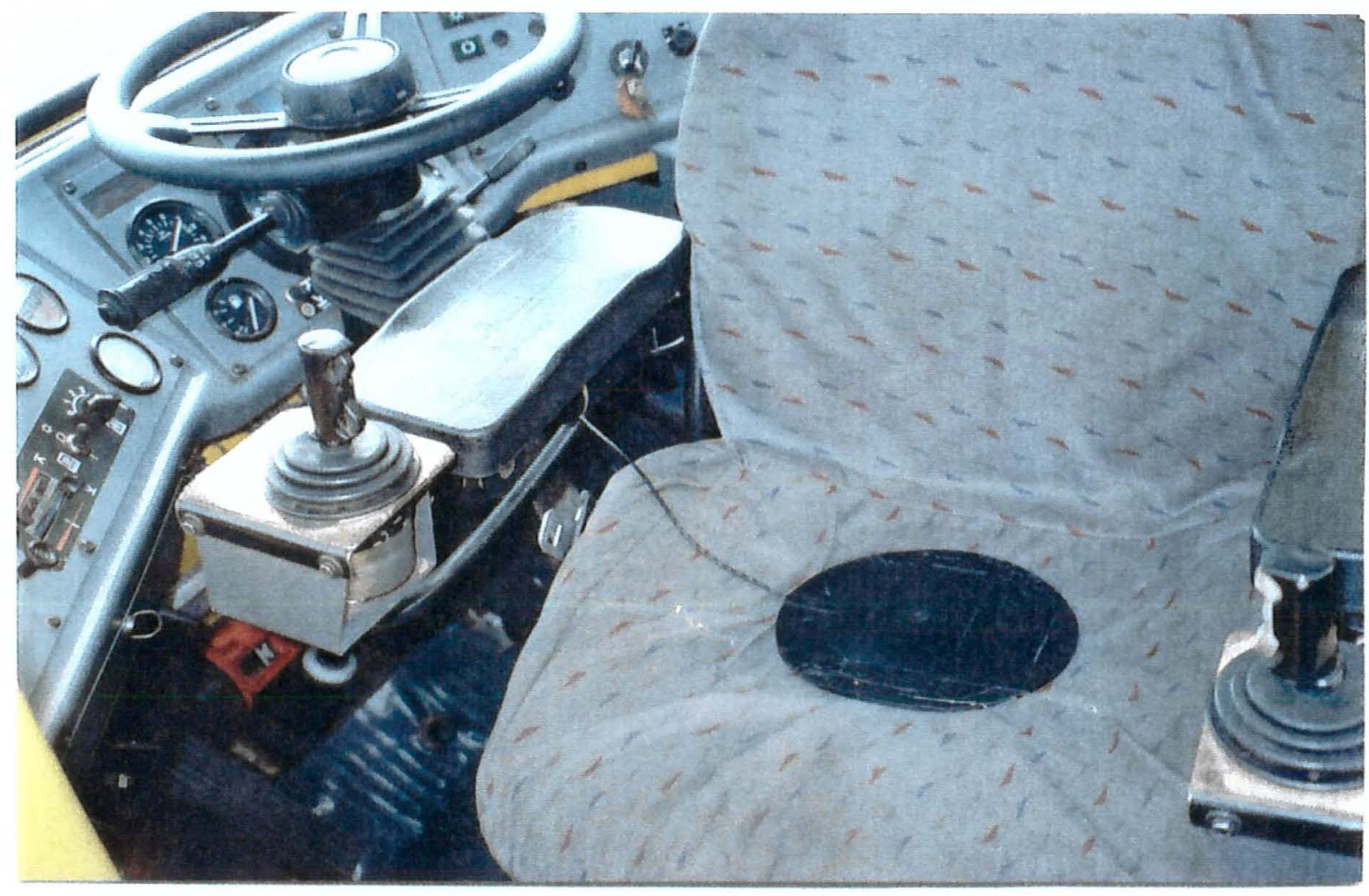

Figura 3 - Fixação do acelerômetro no assento da máquina

Nas avaliações das máquinas colhedoras, o medidor de vibração foi fixado na cabine de forma a não interferir na operação (Figura 4), pois devido ao espaço interno restrito da cabine das máquinas, não foi possível o acompanhamento junto ao operador. Foram tomadas diversas amostras representativas das condições habituais de trabalho, com duração suficiente para cobrir vários ciclos de exposição dos operadores. 


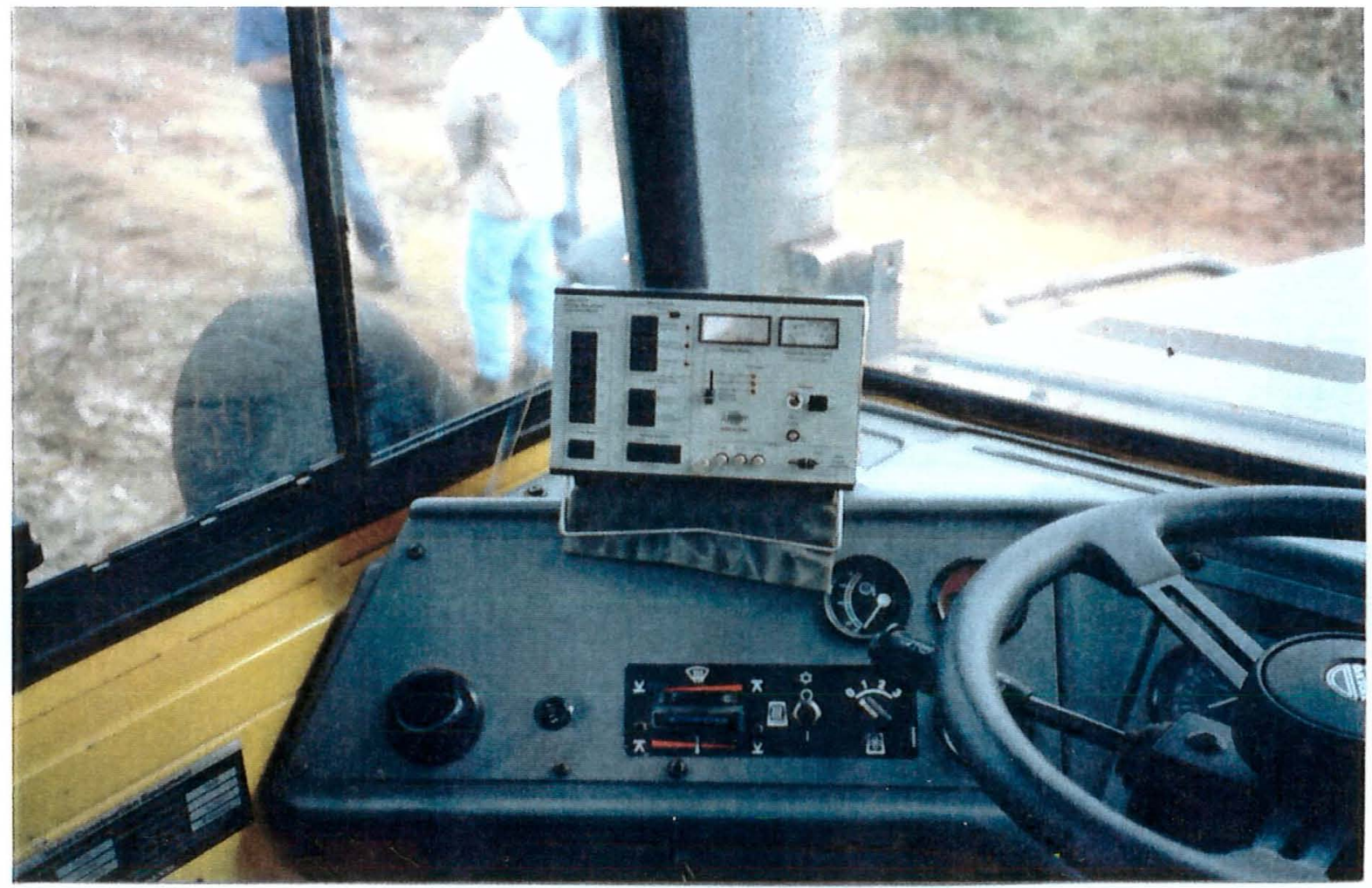

Figura 4 - Fixação do medidor de vibração na cabine da máquina.

$\mathrm{Na}$ avaliação da exposição na operação da máquina carregadora Forwarder, o medidor de vibração foi fixado no interior da cabine e a leitura dos dados foi feita ao longo da operação, com a presença do avaliador, pois a cabine era mais ampla e permitia a permanência de mais uma pessoa. 


\section{RESULTADOS E DISCUSSÃO}

\subsection{Características da atividade de campo}

As atividades de colheita florestal na empresa pesquisada é realizada em três turnos de 8 horas: das 6 às 14 horas, das 14 às 22 horas e das 22 às 7 horas. Ao término de cada turno, um carro da empresa traz o trabalhador do próximo turno, ou o próprio trabalhador vem dirigindo o carro da empresa e o trabalhador que está encerrando o turno leva o carro de volta à administração da empresa.

O transporte dos trabalhadores até a fazenda é feito por ônibus da empresa, que tem horários fixos no decorrer do dia.

A atividade de colheita é realizada por apenas um operador. A máquina é dotada de cabine climatizada, com rádio comunicador que é utilizado para acionar o pessoal de suporte, quando ocorre algum problema mecânico, ou em casos de emergência. $O$ operador é treinado para realizar pequenas manutenções na máquina, não necessitando neste caso do pessoal de suporte. É também orientado a não sujar o interior da máquina, para que a poeira ou terra não comprometa o bom funcionamento dos comandos. 
Todo operador traz em seu turno as ferramentas e serra de corte reserva para uso em caso de manutenção ou rompimento da corrente.

A alimentação, tipo marmitex, é trazida pelo carro da empresa em horários próximos do almoço e deixada em algum lugar próximo ao local de trabalho da máquina, quando o operador está em atividade, o suprimento de água é trazido junto com o operador. $\mathrm{O}$ trabalho é realizado em ambiente uniforme, externamente há um ruído excessivo da máquina, mas o operador não é afetado no interior cabine fechada, a desvantagem é que a comunicação do operador com o exterior, só é possível por meio de sinais ou com o uso do rádio.

O trabalho realizado no período noturno, de acordo com depoimentos do operador, às vezes é prejudicado pela má visibilidade, o que algumas vezes pode provocar acidentes, mas com prejuízo material, não chegando a provocar lesões. Conforme cita Seixas (1998), esse tipo de colhedora possui confiabilidade, apresenta características ergonômicas e ocasiona menor impacto ao ambiente, mas apresenta algumas desvantagens como elevada velocidade de operação e visibilidade restrita.

$\mathrm{Na}$ colheita florestal, o tempo de processamento (corte, desgalhamento e traçamento) de uma árvore com uso da máquina HARVESTER é de aproximadamente $21 \mathrm{~s}$ e é realizado com o acionamento do join stick; com movimentos repetidos de uma das mãos, durante toda a jornada de trabalho.

Inicialmente, a primeira árvore processada serve de guia para a colocação das demais toras em cima (Figura 5 ). Esse procedimento é feito para facilitar a próxima etapa de carregamento das toras de madeira que é feita pela máquina Forwarder (carregadora), de forma a evitar o transporte 
excessivo de terra e/ou galhos. A tora guia escolhida, tem que ter a espessura maior para suportar adequadamente as demais toras. O corte é realizado em quatro linhas e a derrubada ocorre para dentro do talhão, a fim de evitar o perigo de acidentes.

Linhas do talhão

Tora guia

Sentido do caminhamento da máquina

Figura 5 - Esquema do empilhamento das toras após a derrubada e traçamento.

Os equipamentos de proteção individual utilizados pelos operadores são: bota de cano curto, com biqueira de aço, com iluminador no calcanhar, capacete quando estão fora da cabine e uniforme de brim (calça e camisa).

Outra máquina utilizada na colheita é o sling shot, que apresenta funções semelhantes ao harvester. Trata-se de uma adaptação de outras máquinas florestais.

A feller buncher difere das colhedoras anteriores, pois não corta apenas uma árvore de cada vez, a máquina vai abraçando as árvores cortadas e depois são tombadas todas ao mesmo tempo. Esta operação faz com que a máquina tenha maior balanço lateral. Após toda a derrubada, a máquina volta ao talhão para realizar o desgalhamento e o traçamento. A área trabalhada pelo feller buncher é mais adensada, com 2 a 3 brotos por árvore. 
A máquina forwarder é utilizada no transporte das toras para os carreadores.. Os operadores preferem trabalhar na máquina de colheita, pois consideram essa máquina mais ruidosa e com maior vibração durante a sua operação.

\subsection{Descrição das máquinas avaliadas e dos operadores}

Máquina HARVESTER HV 0587; CAT: $320 \mathrm{BL}$; peso: $21.000 \mathrm{Kg}$; sistema rodante: esteira de $800 \mathrm{~mm}$; motor: $134 \mathrm{hp}$; cabeçote HARVESTER;

modelo: Partek 965 BR; peso: $1150 \mathrm{Kg}$; capacidade de corte: $65 \mathrm{~cm}$; capacidade de regulagem do banco: $50 \mathrm{Kg}$ a $120 \mathrm{Kg}$; regulagem do banco durante o ensaio: $60 \mathrm{Kg}$; rendimento: 25 a $30 \mathrm{~m} 3$.

Operador do sexo masculino; idade: 25 anos; peso: $60 \mathrm{Kg}$; produção: 110 árvores/turno; tempo de experiência: 4 anos e 2 meses (tempo em trabalho em turno); trabalho em turno fixo de: 8 horas.

Operador do sexo masculino; peso: $64 \mathrm{KG}$; idade: 36 anos.

Máquina SLINGSHOT - Máquina base da marca Timbertack 608; peso: 20.000; sistema rodante: $610 \mathrm{~mm}$; motor: $167 \mathrm{hp}$; cabeçote da marca Risley, modelo S 1821; capacidade de corte: 21"; peso: $2.630 \mathrm{Kg}$; regulagem banco: $90 \mathrm{Kg}$.

Operador do sexo: masculino; idade: 30 anos; peso: $90 \mathrm{Kg}$; tempo de experiência com operação de máquinas florestais: 8 anos; tempo de experiência com a máquina Slingshot : 3 anos; uso de protetor auricular. 
Máquina FELLER BUNCHER -Máquina base da marca Timbertack 608; peso: 20.000; sistema rodante: $610 \mathrm{~mm}$; motor: $167 \mathrm{hp}$; cabeçote da marca: Hisley; modelo: H1818; deslocamento: 18"; peso: $1950 \mathrm{~kg}$; regulagem do banco: $80 \mathrm{Kg}$.

Operador do sexo masculino; idade: 43 anos; peso: $74 \mathrm{Kg}$; tempo de experiência

Máquina FOWARDER - Marca Volvo A25C ; Motor: 255 hp; grua:

Cramab; peso: $20.500 \mathrm{~kg}$; disco de corte $=32$ "copinhos" redondos;

carregamento de toras de madeira com Fowarder: para toras colhidas com Harvester $=17 \mathrm{~m}^{3} /$ viagem; para toras colhidas com Skingshot $=15 \mathrm{~m}^{3} /$ viagem.

\subsection{Resultados das avaliações de exposição à vibração de corpo inteiro}

Os equipamentos utilizados na medição da exposição à vibração de corpo inteiro têm como base a norma ISO 2631/1:1985. Esta norma sofreu alterações e uma nova versão foi publicada em 1997; uma das alterações ocorridas foi a exclusão dos limites de tolerância, com a inclusão de um guia informativo para avaliar os efeitos da vibração à saúde.

A norma ISO 2631/1:1985 apresenta a vantagem por estabelecer limites de vibração para evitar os possíveis efeitos nocivos decorrentes da exposição à vibração de corpo inteiro, é uma norma mais efetiva do ponto de vista preventivo, conforme a própria referência da norma de 1997.

De acordo a norma ISO 2631/1:1985, para avaliação da vibração de corpo inteiro, a vibração pode atuar em várias direções no corpo humano, na faixa de freqüência de $1 \mathrm{a} 80 \mathrm{~Hz}$, onde a região de maior sensibilidade para o 
eixo $\mathrm{Z}$ encontra-se na faixa de 4 a $8 \mathrm{~Hz}$ e para os eixos $\mathrm{X}$ e $\mathrm{Y}$, na faixa de freqüência de 1 a $2 \mathrm{~Hz}$. 


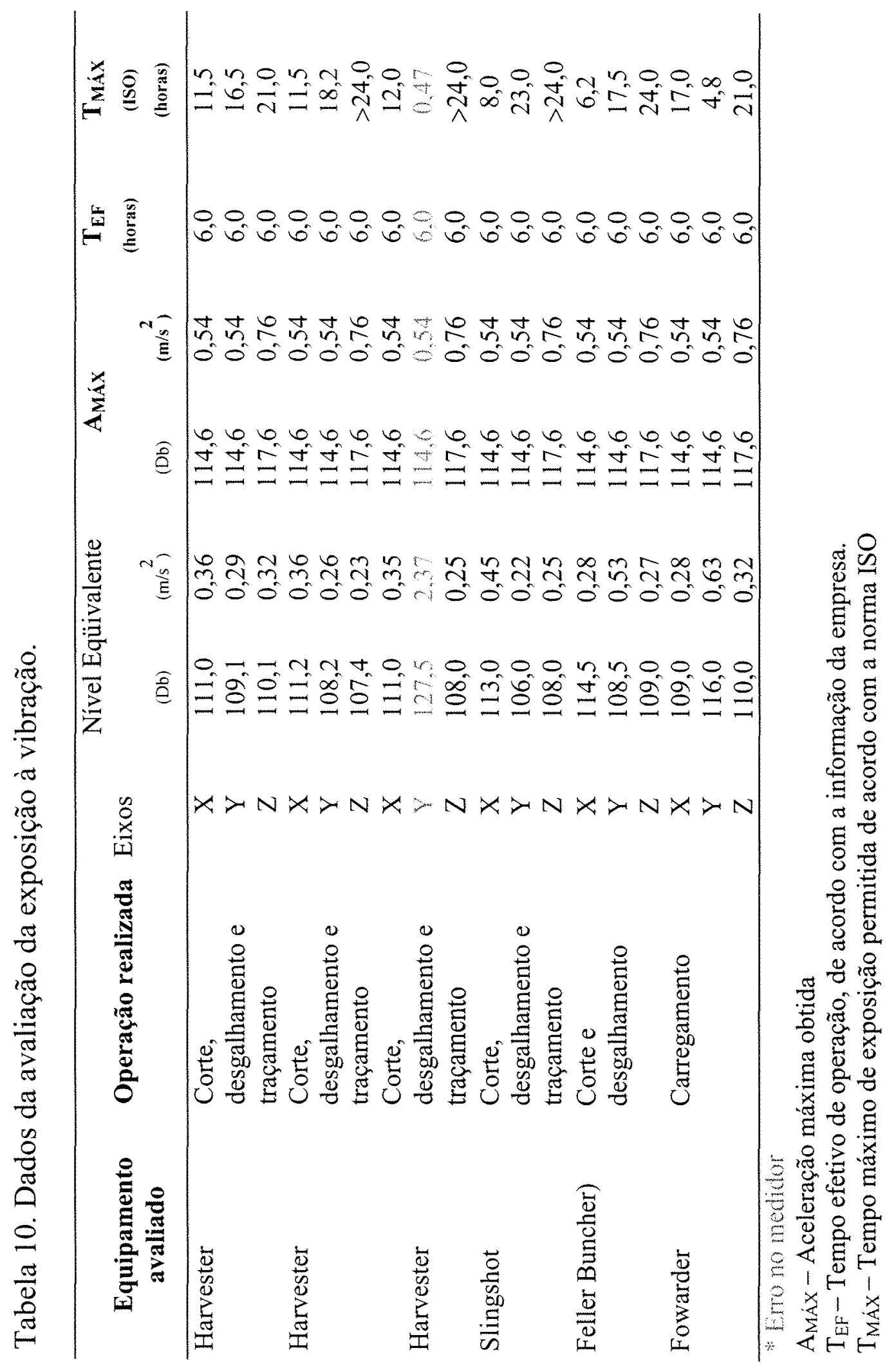


Como se pode observar pela Tabela. 10, para a maioria dos dados apresenta tempo máximo de exposição, muito superiores aos estabelecidos pela ISO 2361-1:1985, às exceções feitas para o valor no eixo $X$, da máquina Feller buncher e para o valor no eixo Y da máquina Forwarder.

Durante os ensaios foi possível perceber, pela observação que essas duas máquinas apresentavam maior balanço durante a operação. As medições obtidas demonstram que o desconforto provocado pela sensação maior ou menor da vibração pode coincidir com os resultados obtidos. Porém, os efeitos da exposição à vibração de corpo inteiro nos diferentes eixos só serão possíveis de verificação, com um acompanhamento médico periódico e ao longo de toda a vida laboral.

As avaliações da exposição a vibração de corpo inteiro são bastante complexas, especialmente no equipamento utilizado, que trabalha em três eixos. Os dados do Harvester apresentados em vermelho são para ilustrar as dificuldades operacionais nos ensaios, quando foram tomadas essas medidas verificou-se que o equipamento passou a tomar medidas não condizentes a situação real da exposição. As dificuldades operacionais são adicionadas às dificuldades de interpretação dos gráficos de exposição, pois os os limites de exposição são obtidos pela interpolação das curvas nos três eixos. A figura 5 mostra uma das curvas apresentadas na norma ISO 26311:1985, para os eixos $X, Y$ utilizadas na obtenção dos tempos limites de exposição, e Figura 6, para eixo. 


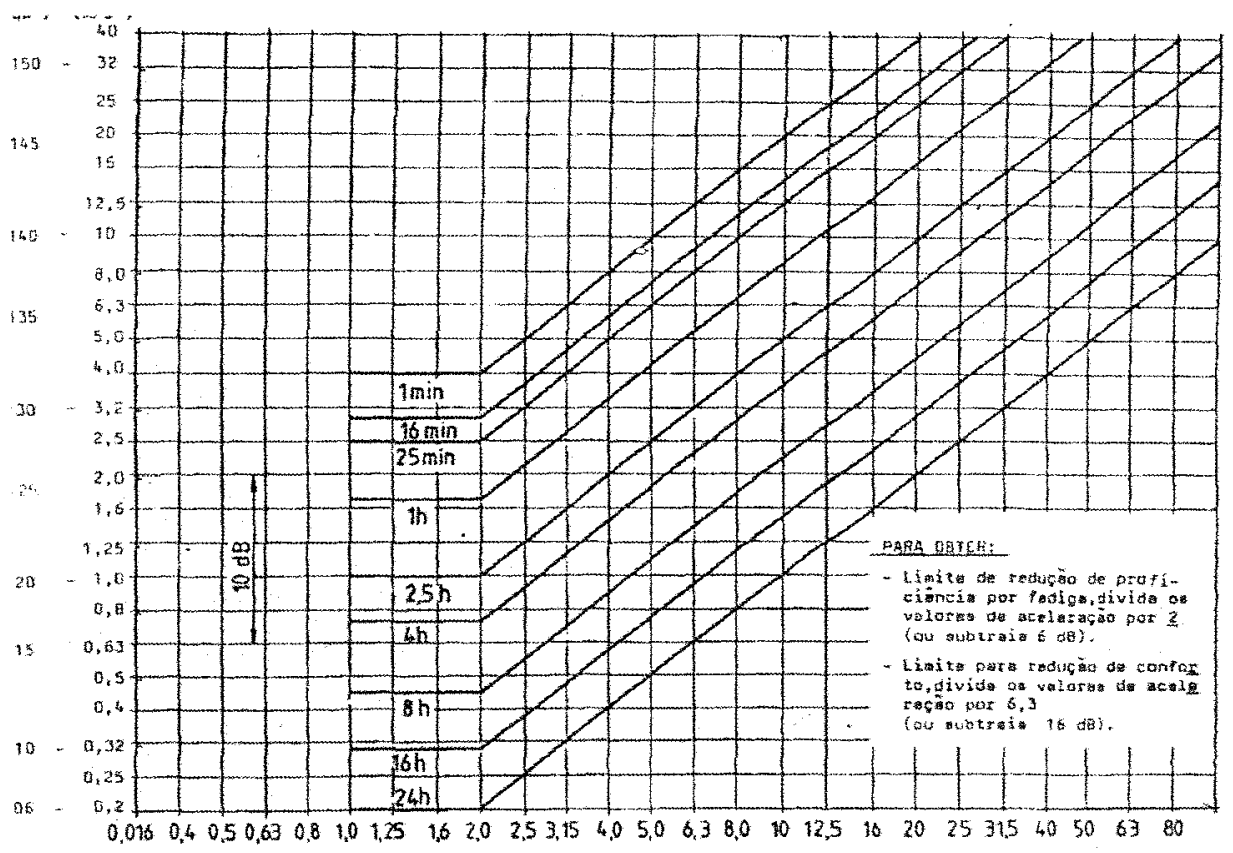

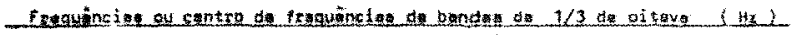

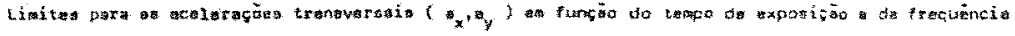

Figura 6- Limites para as acelerações tansversais nos eixos $\mathrm{X}, \mathrm{Y}$.

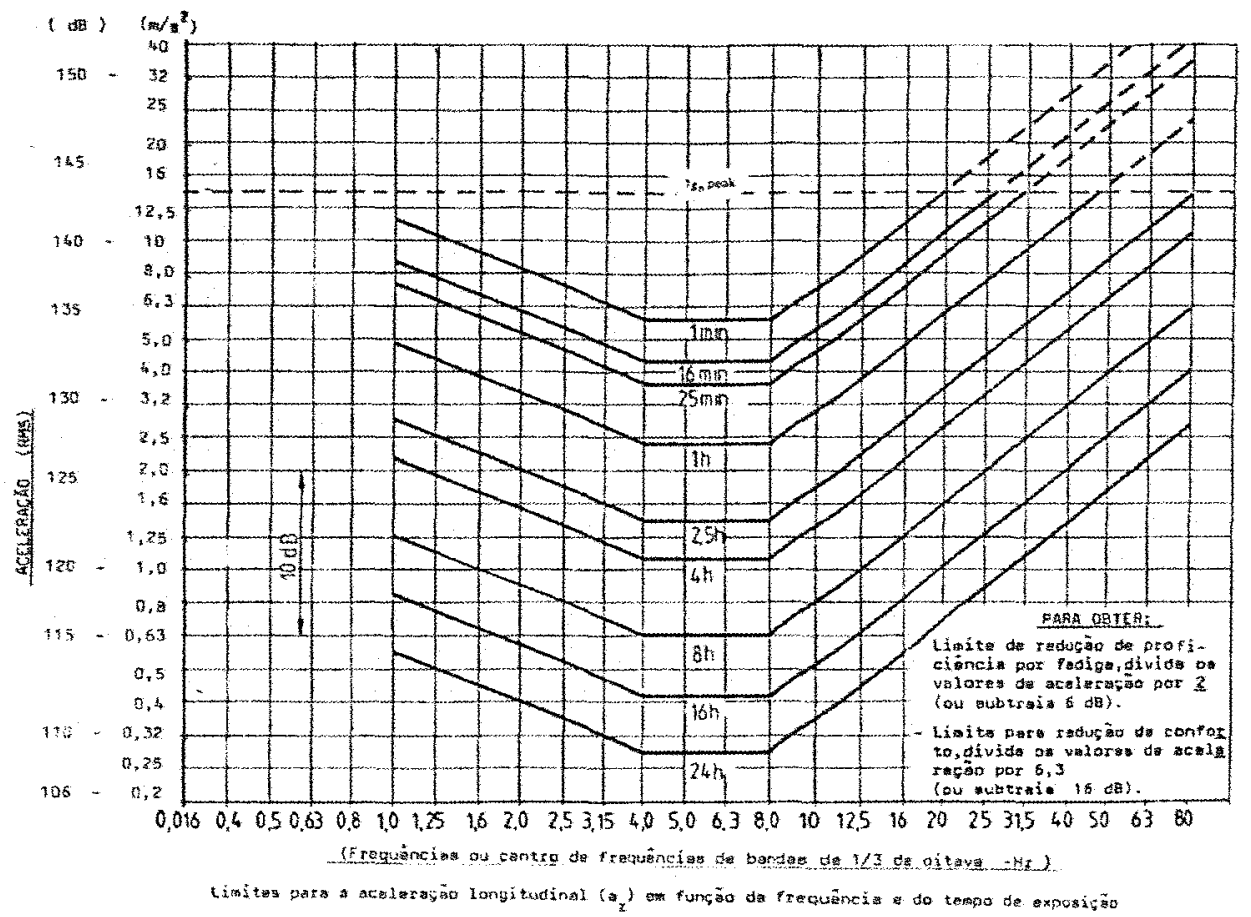

Figura 7- Limites para aceleração no eixo z. 


\section{CONCLUSÕES}

As observações realizadas na situação de trabalho mostraram que as máquinas florestais utilizadas na colheita florestal apresentam diversos aspectos ergonômicos e de segurança favoráveis à manutenção da segurança e conforto do operador. As cabines são climatizadas e, portanto, o calor ou o frio não afeta o conforto do operador. O efeito da vibração é atenuado pelo ajuste do banco ao peso do operador. O banco também é ajustável na altura e no encosto. Alguns aspectos poderiam ser melhorados, como o espaço interno da cabine, para melhorar o conforto do operador e permitir que suas pernas possam ser esticadas, em alguns momentos, para evitar a permanência de uma posição muito estática. O ruído emitido pela máquina é atenuado pela cabine, mas quando o trabalho é executado com as janelas abertas o ruído torna-se intenso.

Um potencial problema que a atividade de colheita pode apresentar é o estresse provocado pela execução de uma atividade solitária, dentro de uma floresta, distante do ponto de apoio administrativo e de convívio social. Apesar da máquina possuir um rádio comunicador, se o operador sofrer de um mal súbito, pode não ter condições de acessar a comunicação. Mesmo que a empresa mantenha um veículo para ronda, pode não estar presente no 
momento de uma emergência. Desta forma, tarefas executadas em áreas muito isoladas deveriam privilegiar o trabalho em dupla, com dois operadores ou com acompanhamento de um veículo de apoio, próximo ao local que está sendo trabalhado.

Uma observação que deve ser levada em conta é a atividade realizada por apenas uma das mãos ao manejar o join stick, com movimentos repetidos dos dedos, podendo levar o operador a contrair lesões de èsforços repetitivos. Para prevenir a ocorrência de algum dano, entretanto, seria necessário efetuar uma análise mais profunda dos movimentos realizados e as suas repetições e investigar quais os exercícios que podem ser realizados e os tempos de pausa.

A execução da tarefa impõe ao operador um estado de alerta constante, pois necessita de atenção acurada para o trajeto da máquina no talhão e a verificação constante da forma de derrubada da árvore, sem danificar as demais. Os perigos de acidentes em atingir alguma pessoa na área trabalhada são mais remotos, pois só é possível a permanência de pessoas autorizadas e de conhecimento do operador.

Os efeitos da vibração no operador de máquinas, como foi discutido anteriormente, necessitam de um estudo mais aprofundado e de longo prazo, com o suporte de demais profissionais das áreas de engenharia, medicina, psicologia, entre outros, para levar em conta todos os fatores externos, como trabalho em turnos, o trabalho monótono, a carga mental e outros problemas decorrentes de esforços por movimentos repetitivos, bem como a susceptibilidade individual, que podem estar em sinergismo com a 
exposição à vibração. Até os dias atuais, mesmo as normas internacionais não apresentam uma resposta conclusiva sobre os limites de tolerância à vibração de corpo inteiro. 


\section{REFERÊNCIAS BIBLIOGRÁFICAS}

ALVES FILHO, J. P. Segurança e saúde do trabalhador rural: aspectos gerais. Boletim Orgânica, v. 1, n.1, p. 11-15, 1999.

AMERICAN CONFERENCE OF GOVERNMENTAL INDUSTRIAL HYGIENISTS. Limites de exposição para substâncias químicas e agentes físicos e índices biológicos de exposição. São Paulo: Associação Brasileira de Higienistas Ocupacionais, 2001. 199 p.

ANASTASI, A. Testes psicológicos. São Paulo: Editora Pedagógica e Universitária; EDUSP, 1975. 762 p.

BRASIL. Ministério da Previdência Social. Estatísticas: os números de acidentes do trabalho no Brasil, 1996/1998. http: www.mpas.gov.br/12_05.htm (09 ago. 2000)

BRASIL. Ministério do Trabalho. Acidentes de trabalho, 1997. http:www.mtb.gov.br/esta/acidentes/acidentes/97/fatais/fatais_c.htm, www.mtb.gov.br/esta/acidentes/acidentes/97/parcial/parcial_c.htm dez. 1999)

COLLETTE, E. Contribuition a l'étude physiopathologique de l'influencedês vibrations de basse frequence sur les conducteurs de tracteurs agricoles. Liège, 1973. 102 p. Grade (Licencie) - Université de.Liège.

CONFERENCIA INTERNACIONAL DEL TRABAJO, 88., Ginebra, 2000. Seguridad y salud en la agricultura. Ginebra: Oficina Internacional del Trabajo, 2000. 108p. 
CUNHA, I. A. Níveis de vibração e ruído gerados por motosserras e sua utilização na avaliação da exposição ocupacional do operador à vibração. Campinas, 2000. 154p. Dissertação (Mestrado) - Faculdade de Engenharia Civil, Universidade Estadual de Campinas.

DYKSTRA, D.P.; HEINRICH, R. Codigo modelo de practicas de aprovechamento forestal de la FAO. Roma: FAO, 1996. 85 p.

FAO. Introduction to ergonomics in forestry in developing countries. Rome, 1992. 200 p.

FAO. Introducción a la ergonomia forestal para países en desarrollo. Roma, 1993. 180p. (Cuadernos Tecnicos de la Fao, 100).

FENNER, P. T. Estudo descritivo dos acidentes de trabalho em uma empresa florestal. Curitiba, 1991. 140p. Dissertação (Mestrado) Universidade Federal do Paraná.

FIATES, G.G.S.; SANTOS, N. O papel do homem na nova organização do trabalho. In: CONGRESSO LATINO AMERICANO DE ERGONOMIA, 4.; CONGRESSO BRASILEIRO DE ERGONOMIA, 8., Florianópolis, 1996. Resumos. Florianópolis: Universidade Federal de Santa Catarina, 1996.

FIEDLER, N.C.; SOUZA, A.P.; MINETTI, L.J.; ANDRADE, S.C. Avaliação qualitativa da ergonomia de concepção de máquinas de colheita de madeira. In: CONGRESSO LATINO AMERICANO DE ERGONOMIA, 4.; CONGRESSO BRASILEIRO DE ERGONOMIA, 8., Florianópolis, 1996. Resumos. Florianópolis: Universidade Federal de Santa Catarina , 1996.

FISCHER, F. M. Trabalho em turnos. Alguns aspectos econômicos, médicos e sociais. São Paulo, 1980. 165 p. Dissertação (Mestrado) Faculdade de Saúde Pública, Universidade de São Paulo. 
FISCHER, F.M.; LIEBER, R.R.; BROWN, F. M. Trabalho em turnos e as relações com a saúde-doença. In: MENDES, R. (Org). Patologia do trabalho. Rio de Janeiro. Editora Atheneu, 1995. p.545-572.

FUNDAÇÃO INSTITUTO BRASILEIRO DE GEOGRAFIA E ESTATÍSTICA. Pesquisa nacional por amostra de domicílios - 1996. http://www.ibge.gov.br/ibge/estatistica/populacao/trabalhoerendime nto/pnad96/default.shtm. (1998)

GARCIA, E. G.; YAMASHITA, R.Y. Panorama de accidentes y enfermidades en el trabajo rural en el Brasil. Educación Obrera, v. $1-2$, p. 84-92, 2000.

GARLIP, R. Setor de plantações florestais no Brasil. In: SEMINÁRIO SOBRE CÓDIGO DE PRÁTICAS E CERTIFICAÇÃO FLORESTAL, 1., Curitiba, 1999. Resumos. Curitiba: Sociedade Brasileira de Silvicultura, 1999. n.p.

GRAMMEL, R. H. A relação entre o desgaste físico e psicológico e o grau de mecanização. In: SEMINÁRIO DE ATUALIZAÇÃO SOBRE SISTEMAS DE COLHEITA DE MADEIRA E TRANSPORTE FLORESTAL, 8., Curitiba, 1994. Curitiba: Universidade Federal do Paraná; Fundação de Pesquisas Florestais do Paraná, 1994. p.194-205.

GRANDJEAN, E. Manual de ergonomia: adaptando o trabalho ao homem. 4.ed. Porto Alegre: Artes Médicas, 1998. 338 p.

IGUTI, A.M. Essor de la production de la canne a sucre au Brésil et influence sur les conditions de travail des conducteurs-chargeurs de canne. Paris, 1989 107p. Thèse de (Doctorat de Troisième Cycle) Université Rene Descartes.

INTERNATIONAL ORGANIZATION FOR STANDARDIZATION ISO - 2631-1: 1985: evaluation of human exposure to whole-body vibration. Part 1: General requirements. Geneva, 1985. 17p. 
JOINT FAO/ECE/ILO COMMITTEE ON FOREST TECHNOLOGY, MANAGEMENT AND TRAINING, Konolfingen, 1996. Safety and health in forestry are feasible! Konolfingen: Federal Office of Environment, Forests and Landscape (FOEFL), 1997. 409 p.

JOINT FAO/ECE/ILO COMMITTEE, Geneva, 1999. Forworknet, industrial activities branch. Geneva: ILO, 1999. 16p.

LAHÓZ, A. A pobreza do debate. Revista Exame, v. 33, n. 20, p. 136143, 1999.

LAVILLE, A. Ergonomia. São Paulo: EPU; EDUSP, 1977. 101 p.

LEÃO, R. M. A floresta e o homem São Paulo: EDUSP; Piraciacaba: Instituto de Pesquisas e Estudos Florestais, 2000. $448 \mathrm{p}$.

MEIRELLES, C.E.; YAMASHITA, R.Y. Segurança do trabalho: um pequeno panorama dos acidentes do trabalho na área rural. In: CONGRESSO BRASILEIRO DE ENGENHARIA AGRÍCOLA, 17., 1988. Anais. Sorocaba: SBEA 1988. p. 709-723.

MENEZES, J.F.; MAZIERO, J.V.; YAMASHITA, R.Y. et al. Avaliação de características de visibilidade apresentadas por um grupo de tratores agrícolas de rodas. Campinas: IAC, 1985. (Boletim Técnico, n.101).

MINETTE, L.J. Análise de fatores operacionais e ergonômicos na operação de corte florestal com motosserra. Viçosa, 1996. 211 p. Tese (Doutorado) - Universidade Federal de Viçosa.

OFICINA INTERNACIONAL DEL TRABAJO. Trabajo. Revista de la OIT, n. 21, p. 8-11, sept./oct. 1997.

OFICINA INTERNACIONAL DEL TRABAJO. Seguridad y salud en el trabajo forestal: repertorio de recomendaciones prácticas de la OIT. Ginebra, 1998. 175p. 
OFICINA INTERNACIONAL DEL TRABAJO. Programa in focus sobre trabajo sin riesgo 2000. http: www.oit.org

ROESLER, E.X. Evolução da mecanização e segurança nos trabalhos de colheita de madeira. In: SEMINÁRIO DE ATUALIZAÇÃO SOBRE SISTEMAS DE COLHEITA DE MADEIRA E TRANSPORTE FLORESTAL, 8., Curitiba, 1994. Anais. Curitiba: Universidade Federal do Paraná: Fundação de Pesquisas Florestais do Paraná, 1994. p.20-38.

RUTENFRANZ, J.; KNAUTH, P.; FISCHER, F. M. Trabalho em turnos e noturno. São Paulo: Editora Hucitec, 1989. 135 p.

SANT'ANNA, C.M.; CARDOSO, A.L.M.; CHAVES, A.A. et al. Melhoria das condições de segurança no uso de motosserras. In: SIMPÓSIO BRASILEIRO SOBRE COLHEITA E TRANSPORTE FLORESTAL, 2., Salvador, 1995. Salvador: s. ed., 1995. p. 173-186.

SANTOS, N.; DUTRA, A.R.A.; RIGHI, C.A.R. et al. A ergonomia dos sistemas de produção. Curitiba: Editora Gênesis, 1997. 353p.

SAYAD, J. Panorama da economia brasileira contemporânea. http: www.brasil.gov.br (jan. 2000)

SEIXAS, F. Mecanização e exploração florestal. Piracicaba: ESALQ, Depto. de Ciências Florestais 1998. 135 p.

SOCIEDADE BRASILEIRA DE SILVICULTURA. Dados estatísticos http://www.sbs.org.br/secure/estatisticas.htm (jan. 2001)

WISNER, A. Ergonomia y condiciones de trabajo. Buenos Aires: Editorial Hvmanitas, 1988. 319 p.

YAMASHITA, R.Y. Motosserras e segurança no Trabalho Revista Fundacentro, v. 1, n. 3, p. 26, out. 1997. 
YAMASHITA, R.Y. Condições de segurança na atividade florestal. Revista Panorama Rural, v. 1, n. 11, p. 68-69, jan. 2000.

YAMASHITA, R.Y. Relatório técnico. São Paulo: FUNDACENTRO, 2001. (Relatório Técnico da Missão de participação na $89^{\mathrm{a}}$ Conferencia Internacional de Trabalho, da Organização Internacional do Trabalho OIT. Genebra, Suíça, 2001). 